\title{
Identification of a Chemoreceptor in Pseudomonas aeruginosa That Specifically Mediates Chemotaxis Toward $\alpha$-Ketoglutarate
}

\section{OPEN ACCESS}

Edited by:

Biswarup Mukhopadhyay, Virginia Tech, USA

Reviewed by:

Birgit Edeltraud Scharf, Virginia Tech, USA

Robert B. Bourret,

University of North Carolina at Chapel Hill, USA

*Correspondence: Tino Krell

tino.krell@eez.csic.es

Specialty section:

This article was submitted to Microbial Physiology and Metabolism, a section of the journal

Frontiers in Microbiology

Received: 19 September 2016 Accepted: 17 November 2016 Published: 29 November 2016

Citation:

Martín-Mora $D$, Ortega $A$,

Reyes-Darias JA, García V, López-Farfán D, Matilla MA and Krell T (2016) Identification of a Chemoreceptor in Pseudomonas aeruginosa That Specifically Mediates Chemotaxis Toward $\alpha$-Ketoglutarate.

Front. Microbiol. 7:1937. doi: 10.3389/fmicb.2016.01937

\section{David Martín-Mora, Alvaro Ortega, José A. Reyes-Darias, Vanina García, Diana López-Farfán, Miguel A. Matilla and Tino Krell*}

Department of Environmental Protection, Estación Experimental del Zaidín, Consejo Superior de Investigaciones Científicas, Granada, Spain

Pseudomonas aeruginosa is an ubiquitous pathogen able to infect humans, animals, and plants. Chemotaxis was found to be associated with the virulence of this and other pathogens. Although established as a model for chemotaxis research, the majority of the $26 P$. aeruginosa chemoreceptors remain functionally un-annotated. We report here the identification of PA5072 (named McpK) as chemoreceptor for $\alpha$-ketoglutarate $(\alpha K G)$. High-throughput thermal shift assays and isothermal titration calorimetry studies (ITC) of the recombinant McpK ligand binding domain (LBD) showed that it recognizes exclusively $\alpha$-ketoglutarate. The ITC analysis indicated that the ligand bound with positive cooperativity $\left(K_{\mathrm{d} 1}=301 \mu \mathrm{M}, K_{\mathrm{d} 2}=81 \mu \mathrm{M}\right)$. McpK is predicted to possess a helical bimodular (HBM) type of LBD and this and other studies suggest that this domain type may be associated with the recognition of organic acids. Analytical ultracentrifugation (AUC) studies revealed that McpK-LBD is present in monomer-dimer equilibrium. Alpha-KG binding stabilized the dimer and dimer self-dissociation constants of $55 \mu \mathrm{M}$ and $5.9 \mu \mathrm{M}$ were derived for ligand-free and $\alpha \mathrm{KG}$-bound forms of McpKLBD, respectively. Ligand-induced LBD dimer stabilization has been observed for other HBM domain containing receptors and may correspond to a general mechanism of this protein family. Quantitative capillary chemotaxis assays demonstrated that $P$. aeruginosa showed chemotaxis to a broad range of $\alpha \mathrm{KG}$ concentrations with maximal responses at $500 \mu \mathrm{M}$. Deletion of the mcpK gene reduced chemotaxis over the entire concentration range to close to background levels and wild type like chemotaxis was recovered following complementation. Real-time PCR studies indicated that the presence of aKG does not modulate mcpK expression. Since $\alpha K G$ is present in plant root exudates it was investigated whether the deletion of $m c p K$ altered maize root colonization. However, no significant changes with respect to the wild type strain were observed. The existence of a chemoreceptor specific for $\alpha \mathrm{KG}$ may be due to its central metabolic role as well as to its function as signaling molecule. This work expands the range of known chemoreceptor types and underlines the important physiological role of chemotaxis toward tricarboxylic acid cycle intermediates.

Keywords: chemotaxis, chemoreceptor, signal transduction, molecular recognition, Pseudomonas aeruginosa, $\alpha$-ketoglutarate 


\section{INTRODUCTION}

Bacteria possess a variety of signal transduction systems that allow them to adapt their metabolism and behavior to different changes in environmental cues. One of the major signal transduction mechanisms is based on the action of chemosensory signaling pathways (Wuichet and Zhulin, 2010). Typically, signaling is initiated by the binding of signals to the chemoreceptor ligand binding domain (LBD), which in turn triggers a molecular stimulus that modulates autophosphorylation of the CheA histidine kinase and consequently transphosphorylation of the CheY response regulator (Hazelbauer et al., 2008). Chemosensory systems carry out multiple functions such as mediating chemotaxis, type IV pili-based motility or alternative cellular processes (Hickman et al., 2005; Zusman et al., 2007; Wuichet and Zhulin, 2010).

Escherichia coli is the traditional model to study chemoreceptor-based signaling processes (Parkinson et al., 2015). This bacterium has 5 chemoreceptors, of which 4 contain a periplasmic 4-helix bundle LBD. The fifth receptor, Aer, causes aerotaxis and has a cytosolic PAS type LBD. Signals bind either directly to the LBD or in complex with a periplasmic ligand binding protein. Chemoreceptors feed into a single chemosensory cascade that mediates chemotaxis toward compounds like sugars, amino acids or dipeptides.

The analysis of 450 bacterial genomes showed that approximately half of them possess genes encoding chemosensory signaling proteins (Wuichet and Zhulin, 2010). Frequently, chemosensory signaling is in many bacteria more complex than in E. coli. Bacteria that possess chemosensory signaling proteins have on average 14 chemoreceptor genes (Lacal et al., 2010b) and for some species up to 60 chemoreceptors were identified (Matsunaga et al., 2005). Genome analyses have furthermore demonstrated that other bacteria possess different types of chemoreceptors that differ in the type of LBD. Most chemoreceptors are functionally un-annotated but such knowledge is indispensable to identify the forces that have shaped the evolution of chemotactic behavior. Chemoreceptors can be classified according to the size of their LBD into cluster I ( $\sim 150$ amino acids $)$ or cluster II ( 250) (Lacal et al., 2010b). Cluster II receptors are absent from E. coli but were estimated to correspond to $40 \%$ of all chemoreceptors (Lacal et al., 2010b). The main representatives of cluster II LBDs are the dCACHE (Liu et al., 2015; Upadhyay et al., 2016) and helical bimodular domain (HBM) (Pineda-Molina et al., 2012; Ortega and Krell, 2014) which, despite their abundance, remain poorly characterized.

The first receptor characterized with an HBM domain was McpS of P. putida KT2440 that mediated chemotactic responses to different Krebs cycle intermediates (Lacal et al., 2010a, 2011a). The 3D structure of the cluster II LBD of McpS revealed that it corresponds to a novel bacterial sensor domain composed of two structural modules that each can bind directly signal molecules (Pineda-Molina et al., 2012). Other HBM domain containing receptors are the citrate specific McpQ of $P$. putida KT2440 (Martin-Mora et al., 2016) as well as McfS (Parales et al., 2013) of P. putida F1 and McpS of P. fluorescens Pf0-1 (Oku et al., 2014) that mediate chemotaxis to organic acids. HBM domains were found to form part of chemoreceptors and sensor kinases and were found in bacteria and archaea (Ortega and Krell, 2014).

Pseudomonas aeruginosa is a ubiquitously occurring microorganism that is capable of causing multiple human opportunistic infections (Gellatly and Hancock, 2013). As such, $P$. aeruginosa is the leading cause of nosocomial infections, particularly in immunocompromised, cancer, burn and cystic fibrosis patients (Juhas, 2015). This, combined with the emergence of strains resistant to all commercially available antibiotics, makes $P$. aeruginosa one of the most feared pathogens (Dorotkiewicz-Jach et al., 2015). In addition, $P$. aeruginosa was found to colonize (Walker et al., 2004) and infect different plants (Cao et al., 2001). A number of reports show that $P$. aeruginosa chemotaxis is necessary for efficient host colonization and virulence (Garvis et al., 2009; McLaughlin et al., 2012; Kamath et al., 2016; Schwarzer et al., 2016) and the interference with the motility and chemotaxis was proposed as an alternative strategy to block this pathogen (Erhardt, 2016).

Pseudomonas aeruginosa is a model organism to study chemotaxis (Kato et al., 2008; Sampedro et al., 2015). In particular its responses to amino acids by the three paralogous receptors PctA, PctB, and PctC (Kuroda et al., 1995; Taguchi et al., 1997; Rico-Jimenez et al., 2013; McKellar et al., 2015; Reyes-Darias et al., 2015a,b) as well as its response to inorganic phosphate (Wu et al., 2000; Rico-Jimenez et al., 2016) by the CtpL and $\mathrm{CtpH}$ receptors have been studied in some depth. In addition, the cytosolic and atypical receptor McpB (also named Aer2) (Watts et al., 2011; Airola et al., 2013; Garcia-Fontana et al., 2014; Garcia et al., 2016) was subject to many studies and is amongst the best studied members of the chemoreceptor sub-family with cytoplasmic location. Chemoreceptor PA2652 was identified as a specific malate chemoreceptor (AlvarezOrtega and Harwood, 2007) and TlpQ responsible for the chemotaxis toward the plant hormone ethylene (Kim et al., 2007). Two other chemoreceptors, WspA and BdlA, play important roles in biofilm formation and dispersion (Hickman et al., 2005; Morgan et al., 2006; O'Connor et al., 2012; Petrova and Sauer, 2012). However, of the 26 P. aeruginosa chemoreceptors more than half remain of unknown function. This knowledge, however, is indispensable to understand the forces that have driven the evolution of chemotaxis in this ubiquitous pathogen.

Pseudomonas aeruginosa $\mathrm{PAO} 1$ has three receptors with an HBM domain. One of them, CtpL, was found to mediate specifically chemotaxis to low Pi concentrations (Wu et al., 2000). However, CtpL does not bind Pi directly but recognizes the Pi loaded periplasmic binding protein PstS (Rico-Jimenez et al., 2016). The remaining two receptors, PA1646 and PA5072, are of unknown function. We report here the functional annotation of one of them, PA5072, that binds and mediates chemotaxis exclusively to $\alpha$-ketoglutarate ( $\alpha \mathrm{KG})$. This receptor, 
termed McpK, expands the range of known chemoreceptor types.

\section{MATERIALS AND METHODS}

\section{Bacterial Strains, Plasmids and Primers}

The strains and plasmids used in this study are listed in Table 1. Different primers for molecular biology manipulations are provided in Supplementary Table S1.

\section{Construction of Expression Plasmid for McpK-LBD}

The DNA fragment of $m c p K$ encoding amino acids $\mathrm{Arg}^{38}$ Ser $^{293}$ was amplified using primers McpK-LBD_fw and McpKLBD_rv and genomic DNA of $P$. aeruginosa PAO1. The resulting PCR product was cloned into pGEM-T and digested with NdeI and BamHI and then subcloned into the expression plasmid pET28b(+) linearized with the same enzymes. The resulting plasmid, termed pET28-McpK-LBD, was verified by DNA sequencing of the insert and flanking regions.

\section{Overexpression and Purification of McpK-LBD}

Escherichia coli BL21 (DE3) containing pET28-McpK-LBD was grown in $2 \mathrm{~L}$ Erlenmeyer flasks containing $500 \mathrm{ml} \mathrm{LB}$ medium supplemented with $50 \mu \mathrm{g} \mathrm{m}{ }^{-1}$ kanamycin at $30^{\circ} \mathrm{C}$ until an $\mathrm{OD}_{660}$ of 0.6 , at which point protein production was induced by adding $0.1 \mathrm{mM}$ isopropyl- $\beta$-D-1-thiogalactopyranoside (IPTG). Growth was continued at $18^{\circ} \mathrm{C}$ overnight before cell harvest by centrifugation at $10,000 \mathrm{~g}$ for $30 \mathrm{~min}$. All subsequent manipulations were carried out at $4^{\circ} \mathrm{C}$. Cell pellets were resuspended in buffer A [20 mM Tris/ $\mathrm{HCl}, 200 \mathrm{mM} \mathrm{NaCl}, 10 \mathrm{mM}$ imidazole, 5\% (vol/vol) glycerol, $\mathrm{pH}$ 8.0] and broken by French press treatment at 1000 psi. After centrifugation at 20,000 $g$ for $1 \mathrm{~h}$, the supernatant was loaded onto a $5 \mathrm{ml}$ HisTrap column (Amersham Bioscience), washed with five column volumes of buffer $\mathrm{A}$ and eluted with a $30-300 \mathrm{mM}$ imidazole gradient in buffer A. Protein-containing fractions were pooled.

\section{Thermal Shift Assays}

Thermal shift assays were performed using a BioRad MyIQ2 Real-Time PCR instrument. Ligands were prepared by dissolving

TABLE 1 | Bacterial strains and plasmids used in this study.

Strain or plasmid

Relevant characteristics

\section{Strains}

Escherichia coli BL21 (DE3)

E. coli $\mathrm{DH} 5 \alpha$

E. coli HB101

E. coli CC118גpir

Pseudomonas aeruginosa PAO1

$P$. aeruginosa $\mathrm{PAO} 1-\mathrm{Km}$

$P$. aeruginosa PAO1 $\triangle m c p K$

Plasmids

pGEM-T

pET28b(+)

p34S-Km3

pET28-McpK-LBD

pUC18Notl

pUC18Notl-5072Up

pMAMV257

pMAMV258

pUC18Notl-5072UpDw

pKNG101

pKNG101-PA5072UpDw

pMAMV261

pRK600

pBBR1MCS-2

pBBR1MCS-2-McpK

thi-1

Reference strain

$A p^{r}$; TA-cloning vector into pKNG101
F-, ompl, hsdS $S_{\mathrm{B}}\left(\mathrm{r}^{-}{ }_{\mathrm{B}} \mathrm{m}^{-} \mathrm{B}\right) \mathrm{gal}$, dam, met

supE44 lacU169 (Ø80lacZ $\Delta \mathrm{M} 15)$ hsdR17 $\left(r_{\mathrm{k}}{ }^{-} m_{\mathrm{k}}{ }^{-}\right)$, recA1 endA1 gyrA96 thi-1 relA1

F- $\Delta$ (gpt-proA)62 leuB6 supE44 ara-14 galK2 lacY1 $\Delta$ (mcrC-mrr) rpsL20 (Sm ${ }^{r}$ xyl-5 mtl-1 recA13

Rifr; $\Delta$ (ara-leu) araD $\Delta$ lacX74 galE galK phoA20 thi-1 rpsE rpoB argE(Am) recA1 Tn7 $\lambda$ pir

$\mathrm{Km}^{\mathrm{r}}$; wild type PAO1 with a $\mathrm{Km}$ cassette inserted in a neutral position downstream of $\mathrm{g} / \mathrm{mS}$

$P$. aeruginosa PAO1 deletion mutant of $\Delta m c p K$ gene

$\mathrm{Km}^{\mathrm{r}}$; Protein expression plasmid

$\mathrm{Km}^{r}, \mathrm{Ap}^{\mathrm{r}} ; \mathrm{Km} 3$ antibiotic cassette

$\mathrm{Km}^{r} ; \mathrm{pET} 28 \mathrm{~b}(+)$ derivative containing DNA fragment encoding McpK-LBD

Apr ; ori pMB1, similar to pUC18 but with Notl sites flanking the MCS; cloning vector

$\mathrm{Ap}^{r}$; pUC18Notl derivative containing a 0.3-kb Hindlll-Xbal fragment of upsteam region of pa5072

$\mathrm{Ap}^{r}$; 1.4-kb PCR product containing the intergenic region between genes pa5548 and pa5549 ( $\mathrm{g} / \mathrm{mS})$ of $P$. aeruginosa PAO1 was inserted into the EcoRI/Hindlll sites of pUC18Notl. A BamHI site was inserted into this intergenic region by PCR.

$\mathrm{Ap}^{\mathrm{r}}, \mathrm{Km}^{\mathrm{r}}$; 0.96-kb BamHI fragment containing $\mathrm{km} 3$ cassette of $\mathrm{p} 34 \mathrm{~S}-\mathrm{Km} 3$ was inserted into the BamHI downstream of $\mathrm{g} / \mathrm{mS}$ in pMAMV257

$\mathrm{Ap}^{\mathrm{r}}$; pUC18Notl derivative containing a 1-kb HindllI-EcoRl fragment containing upstream and downstream region of pa5072

$\mathrm{Sm}^{r}$; oriR6K, mob, sac; suicide vector

$\mathrm{Sm}^{r}$; pKNG101derivative containing a $0.6 \mathrm{~Kb}$ Notl fragment from pUC18Notl-5072UpDw cloned

$\mathrm{Sm}^{r}, \mathrm{Km}^{\mathrm{r}} ; 2.4-\mathrm{kb}$ Notl fragment of pMAMV258 was cloned the same site in pKNG101

$\mathrm{Cm}^{r}$; oriColE1, RK2 $\mathrm{mob}^{+}$, tra ${ }^{+}$; helper plasmid

$\mathrm{Km}^{r}$; broad-host-range cloning plasmid pBB1MCS derivative containing $\mathrm{Km}^{\mathrm{r}}$ cassette, $\mathrm{mob}^{+}$, rep ${ }^{+}$

$\mathrm{Km}^{\mathrm{r}}$; pBBR1MCS-2 derivative containing mcpK gene and its $607 \mathrm{bp}$ upstream region
Reference or source

Jeong et al., 2009

Woodcock et al., 1989

Boyer and Roulland-Dussoix,

1969; Kessler et al., 1992

Herrero et al., 1990

Stover et al., 2000

This study

This study

Promega

Novagen

Dennis and Zylstra, 1998

This study

Purchased from Biomedal

This study

This study

This study

This study

Kaniga et al., 1991

This study

This study

de Lorenzo et al., 1990

Kovach et al., 1995

This study

The following abbreviations were used for antibiotics: km, kanamycin; cm, chloramphenicol; ap, ampicillin; rif, rifampicin; sm, streptomycin. 
Biolog Phenotype Microarray compounds in $50 \mu \mathrm{l}$ of MilliQ water to obtain a final concentration of around 10-20 mM (as indicated by the manufacturer). Screening was performed with plates PM1, PM2A, PM3B, PM4A, and PM5. Each plate contains 95 compounds and a control (Supplementary Figure $\mathrm{S} 1)$. Each $25 \mu \mathrm{l}$ assay mixture contained $40 \mu \mathrm{M}$ protein in $5 \mathrm{mM}$ Tris, $5 \mathrm{mM}$ Pipes, $5 \mathrm{mM}$ Mes, pH8.0 and SYPRO orange (Life Technologies) at $5 \mathrm{x}$ concentration. Aliquots of $2.5 \mu \mathrm{l}$ of the resuspended Biolog compounds were added to each well. Samples were heated from $23^{\circ} \mathrm{C}$ to $85^{\circ} \mathrm{C}$ at a scan rate of $1^{\circ} \mathrm{C} / \mathrm{min}$. The protein unfolding curves were monitored by detecting changes in SYPRO Orange fluorescence. Melting temperatures were determined using the first derivative values from the raw fluorescence data.

\section{Isothermal Titration Calorimetry}

Experiments were conducted on a VP-microcalorimeter (Microcal, Amherst, MA, USA) at $20^{\circ} \mathrm{C}$ or $10^{\circ} \mathrm{C}$. McpKLBD was dialyzed overnight against $5 \mathrm{mM}$ Tris, $5 \mathrm{mM}$ PIPES, $5 \mathrm{mM}$ MES, $\mathrm{pH} 8.0$ and placed into the sample cell. Typically, protein at $20-100 \mu \mathrm{M}$ was introduced into the sample cell and titrated with 1-3 mM ligand solutions that were prepared in dialysis buffer immediately before use. For fitting, data were integrated using NITPIC (Keller et al., 2012) before global fitting to a two symmetric-site binding model in SEDPHAT (Houtman et al., 2007). The binding constants expressed are corrected as $K_{\mathrm{d}} 1=2^{*} K_{\mathrm{d}} 1^{\prime}$ and $K_{\mathrm{d}} 2=0.5^{*} K_{\mathrm{d}} 2^{\prime}$ in order to express an estimation of the microscopic constants for the two binding sites model, where $\mathrm{Kx}$ ' are the macroscopic constants measured. The cooperativity factor $\alpha$ is expressed as $\alpha=K_{\mathrm{d}} 1 / K_{\mathrm{d}} 2$. Statistical uncertainties for best-fit estimates of $K_{\mathrm{d}}$ and $\Delta H$ were calculated using standard error surface projection methods built into SEDPHAT.

\section{Analytical Ultracentrifugation}

Experiments were performed in a Beckman Coulter Optima XL-I analytical ultracentrifuge (Beckman-Coulter, Palo Alto, CA, USA) equipped with UV-visible absorbance as well as interference optics detection systems, using an An50Ti 8-hole rotor and $12 \mathrm{~mm}$ path-length charcoal-filled epon double-sector centerpieces. The experiments were carried out at $7^{\circ} \mathrm{C}$ with at least $1 \mathrm{~h}$ stabilizing after reaching $7^{\circ} \mathrm{C}$ in the rotor chamber, using $5 \mathrm{mM}$ Tris, $5 \mathrm{mM}$ PIPES, $5 \mathrm{mM}$ MES, pH 8.0. Samples of 10-50 $\mu \mathrm{M}$ for McpK$\mathrm{LBD}$ were analyzed in the presence and absence of $1 \mathrm{mM}$ $\alpha \mathrm{KG}$.

Sedimentation velocity (SV) runs were carried out at a rotor speed of $128,793 \times \mathrm{g}$ using $400 \mu \mathrm{L}$ samples with McpKLBD dialysis buffer as reference. A series of 180 scans without time intervals between successive scans were acquired for each sample. Laser at a wavelength of $236 \mathrm{~nm}$ was used in the absorbance optics mode. A least squares boundary modeling of the SV data was used to calculate sedimentation coefficient distributions with the size-distribution $c(s)$ method and the noninteracting discrete species model (Schuck, 2000) implemented in the SEDFIT v14.1 software. The molecular weight was extracted from the sedimentation profiles, via the Lamm equation solution included in the $c(s)$ model of SEDFIT (Schuck, 2000). The best fit values obtained for the sedimentation coefficient $(s$, in $\mathrm{S}$ or Svedbergs) and diffusion were used to estimate the molar mass of the molecule using the Svedberg equation. Buffer density $(\rho=1.00036 \mathrm{~g} / \mathrm{ml})$ and viscosity $(\eta=0.01433$ Poise $)$ at $7^{\circ} \mathrm{C}$ were estimated by SEDNTERP software (Laue et al., 1992) from the buffer components. The partial specific volume used was $0.71274 \mathrm{ml} / \mathrm{g}$ as calculated from the amino acid sequence also using SEDNTERP software.

Sedimentation equilibrium (SE) experiments were performed at $7^{\circ} \mathrm{C}$, measuring absorbance at $280 \mathrm{~nm}$ as a function of radius. Three different concentrations of $\operatorname{McpK}-\operatorname{LBD}(40,50$, and $60 \mu \mathrm{M})$ both in the absence or in the presence of $1 \mathrm{mM} \alpha \mathrm{KG}$ were loaded with the dialysis buffer as reference and a multispeed $(9,740,20,606$, and $185,462 \times \mathrm{g})$ run was used. The data were analyzed globally by the SEDPHAT (Vistica et al., 2004) "species analysis with mass conservation constraints" model. The goodness of fit was evaluated on the basis of the residuals, expressed as the difference between the experimental data and the theoretical curve.

\section{Construction of $P$. aeruginosa PAO1 $\Delta$ pa5072 ( $\Delta$ mcpK)}

An unmarked non-polar deletion of pa5072 was created by allelic exchange as described (Schweizer, 1992) with the following modifications: two DNA fragments comprising the 234 bp upstream and 336 bp downstream regions of pp5072 were obtained by PCR amplification of genomic DNA using primers PA5072UpF-HindIII and PA5072UpR-XbaI (upstream region) and primers PA5072DownF-XbaI and PA5072DownR-EcoRI (downstream region). The upstream DNA fragment was digested with HindIII and XbaI and cloned into pUC18NotI digested with the same restriction enzymes, resulting in pUC18NotI5072Up, whereas the downstream DNA fragment was digested with XbaI and EcoRI and cloned into pUC18NotI-5072Up digested with the same restriction enzymes, resulting in pUC18NotI-5072UpDw. The 570 bp 5072UpDw DNA fragment was digested from pUC18NotI-5072UpDw using NotI and subcloned into the suicide vector pKNG101 a mobilizable suicide vector, hosted routinely in the permissive $E$. coli strain CC118 $\lambda$ pir bearing the positive counter selection marker $s a c B$ and conferring resistance to streptomycin. The resulting plasmid, pKNG101-PA5072UpDw was transformed into E. coli CC118 $\lambda$ pir. The pKNG101-PA5072UpDw plasmid was mobilized from this strain into $P$. aeruginosa PAO1 by three-partner conjugation using the E. coli HB101(pRK600) helper strain. Selection for plasmid cointegration in $P$. aeruginosa PAO1 was accomplished using M9 minimal medium supplemented with $10 \mathrm{mM}$ succinate and $2000 \mu \mathrm{g} / \mathrm{ml}$ streptomycin (Sm). The $\mathrm{Sm}^{\mathrm{r}}$ colonies were unable to grow on LB medium containing $10 \%$ sucrose (Suc), confirming that the plasmid pKNG101-PA5072UpDw with its $s a c B$ gene had integrated into $P$. aeruginosa PAO1. Transconjugants were plated on LB plates and incubated for $48 \mathrm{~h}$ at room temperature. PCR analysis of the $\mathrm{Suc}^{\mathrm{r}} \mathrm{Sm}^{\mathrm{s}}$ colonies confirmed that gene replacement had occurred. 


\section{Construction of Plasmid for Complementation}

The DNA fragment corresponding to the $m c p K$ gene and the 607 bp upstream region was amplified by PCR using primers McpK-comp_fw and McpK-comp_rv and genomic DNA of $P$. aeruginosa $\mathrm{PAO}$. The resulting fragment was digested with $\mathrm{KpnI}$ and $\mathrm{XbaI}$ and cloned into pBBR1MCS-2, linearized with the same enzymes. The resulting plasmid pBBR1MCS-2-McpK was verified by DNA sequencing of the insert and flanking regions. The mutant strain was transformed with pBBR1MCS-2-McpK by electroporation $(2800 \mathrm{~V})$. Transformed colonies were selected on LB agar plates containing $300 \mu \mathrm{g} / \mathrm{ml}$ kanamycin and verified by colony PCR.

\section{Quantitative Capillarity Chemotaxis Assays}

Assays were carried out at a temperature of $25^{\circ} \mathrm{C}$. Bacterial cultures were grown to an $\mathrm{OD}_{600}$ of $0.35-0.4$ in MS medium, washed and resuspended in chemotaxis buffer $\left(30 \mathrm{mM} \mathrm{K}_{2} \mathrm{HPO}_{4}\right.$, $19 \mathrm{mM} \mathrm{KH}_{2} \mathrm{PO}_{4}, 20 \mu \mathrm{M}$ EDTA and $0.05 \%$ (v/v) glycerol, $\mathrm{pH}$ 7.0 ) to an $\mathrm{OD}_{600}$ of $0.08-0.1$. Polystyrene multi-well plates were filled with $230 \mu \mathrm{l}$ of the resulting bacterial suspension. For filling with chemoeffector solutions, capillaries (Microcaps, Drummond Scientific, USA) were heat-sealed at one end, warmed over the flame and the open end inserted into the chemoattractant solution. The capillary was immersed into the cell suspension at its open end. After incubation for $30 \mathrm{~min}$, the capillary was removed from the cell suspension, rinsed with water and emptied into an Eppendorf tube containing $1 \mathrm{ml}$ M9 medium. Serial dilutions were made and $20 \mu \mathrm{l}$ aliquots of the resulting cell suspension were plated onto agar plates containing M9 minimal medium supplemented with $15 \mathrm{mM}$ succinate and incubated at $30^{\circ} \mathrm{C}$. Colonies were counted after growth for $24 \mathrm{~h}$. Positive (casamino acids) and negative (buffer only) controls were included in each experiment. Data shown are means from three independent experiments conducted in triplicate.

\section{RNA Extraction and RT-qPCR Analysis}

Two flasks with $20 \mathrm{ml}$ of minimal medium M9 containing $10 \mathrm{mM}$ glucose were inoculated with an overnight culture to an $\mathrm{OD}_{600}$ of 0.05. At mid-exponential phase, $1 \mathrm{mM}$ of $\alpha \mathrm{KG}$ was added to one of the flasks and $0.5 \mathrm{ml}$ samples were taken after 0 , 15, 30, and $45 \mathrm{~min}$. Total RNA was extracted using the High Pure RNA Isolation Kit (Roche Diagnostics) according to the manufacturer's instructions. RNA was treated with Turbo DNAse (Ambion) and the RNA quality and quantity was analyzed by NanoDrop Spectophotometer and agarose gel electrophoresis. cDNA was synthesized from 500 ng of RNA using the SuperScript II Reverse Transcriptase (Invitrogene) and $200 \mathrm{ng}$ of random primers following manufacturers' instructions. Quantitative PCR was performed using the iQ SYBR green supermix (BIO-RAD) in a $\mathrm{MyiQ}^{\mathrm{TM}} 2$ thermocycler (BIO-RAD). The PCR protocol used was $95^{\circ} \mathrm{C}$ for $5 \mathrm{~min}$ followed by 35 cycles of $95^{\circ} \mathrm{C}(10 \mathrm{~s})$ and $60^{\circ} \mathrm{C}(30 \mathrm{~s})$ and melting curve analysis from 55 to $95^{\circ} \mathrm{C}$, with increment of $0.5^{\circ} \mathrm{C} / 10 \mathrm{~s}$. Gene expression data were normalized to the expression of the reference gene $r p o D$ and reported as normalized fold expression. The primers for $m c p K$ and $r p o D$ were designed using the Primer3 Plus software.

\section{Construction of the Strain PAO1-Km}

The kamanycin-resistant strain $P$. aeruginosa PAO1-Km was constructed by homologous recombination using a derivative plasmid of the suicide vector pKNG101. The initial plasmid pMAMV257 was generated by separately amplifying the $5^{\prime}$ ends of the convergently transcribed genes pa5548 and pa5549 $(\mathrm{glmS})$ of $P$. aeruginosa PAO1. These PCR products were obtained using primers glmS-EcoRI_fw and gmlS-BamHI_rv (for amplifying $5^{\prime}$ end of $g l m S$ ) and glmS-BamHI_fw and glmS-HindIII_rv (for amplifying $5^{\prime}$ end of pa5548). Subsequently, the PCR products were digested with EcoRI and BamHI ( $5^{\prime}$ end of $g \operatorname{lm} S$ ) or BamHI and HindIII ( $5^{\prime}$ end of pa5548) and ligated in a three-way ligation into pUC18Not. For the generation of the final PAO1-Km strain, the suicide plasmid pMAMV261 was transferred to $P$. aeruginosa PAO1 by triparental conjugation using E. coli CC118גpir and E. coli HB101 (pRK600) as helper. PAO1 cells, in which pMAMV261 has integrated into the chromosome, were selected on minimal medium containing $400 \mu \mathrm{g} / \mathrm{ml}$ streptomycin and $200 \mu \mathrm{g} / \mathrm{ml}$ kanamycin. To select derivatives that had undergone a second crossover event, sucrose was added to a final concentration of $10 \%$ $(\mathrm{w} / \mathrm{v})$. The final PAO1-Km strain was confirmed by PCR and sequencing.

\section{Competitive Root Colonization Assays}

Sterilization, germination and inoculation of maize seeds was carried out as described previously, with minor modifications (Matilla et al., 2007). Briefly, sterile seeds were incubated for $1 \mathrm{~h}$ at $30^{\circ} \mathrm{C}$ with a $10^{7} \mathrm{CFU} / \mathrm{ml} 1: 1$ mixture of PAO1-Km and $\Delta m c p K$. Thereafter, seeds were rinsed with sterile deionized water and planted in $50 \mathrm{ml}$ Sterilin tubes containing $40 \mathrm{~g}$ of sterile washed silica sand and $10 \%(\mathrm{v} / \mathrm{w})$ plant nutrient solution supplemented with Fe-EDTA and micronutrients. Plants were maintained at $24^{\circ} \mathrm{C}$ with a daily light period of $16 \mathrm{~h}$. After 7 days, bacterial cells were recovered from the rhizosphere or from $1 \mathrm{~mm}$ of the main root apex, as described previously (Matilla et al., 2007). Serial dilutions were plated in LB-agar and LB-agar medium supplemented with $400 \mu \mathrm{g} / \mathrm{ml}$ of kanamycin, to select the wild type strain $\mathrm{PAO} 1-\mathrm{Km}$.

\section{RESULTS}

\section{$\alpha$-Ketoglutarate Causes the Most Pronounced Increase in Thermal Stability of the PA5072-LBD}

To identify the putative LBD of chemoreceptor PA5072, its sequence was analyzed using the DAS transmembrane prediction algorithm (Cserzo et al., 1997). Two transmembrane regions were identified that flank the segment of amino acids 38-293, which likely corresponds to the periplasmic LBD (Supplementary Figure S2). The DNA fragment encoding the PA5072-LBD was cloned into an expression vector, the protein overexpressed in 


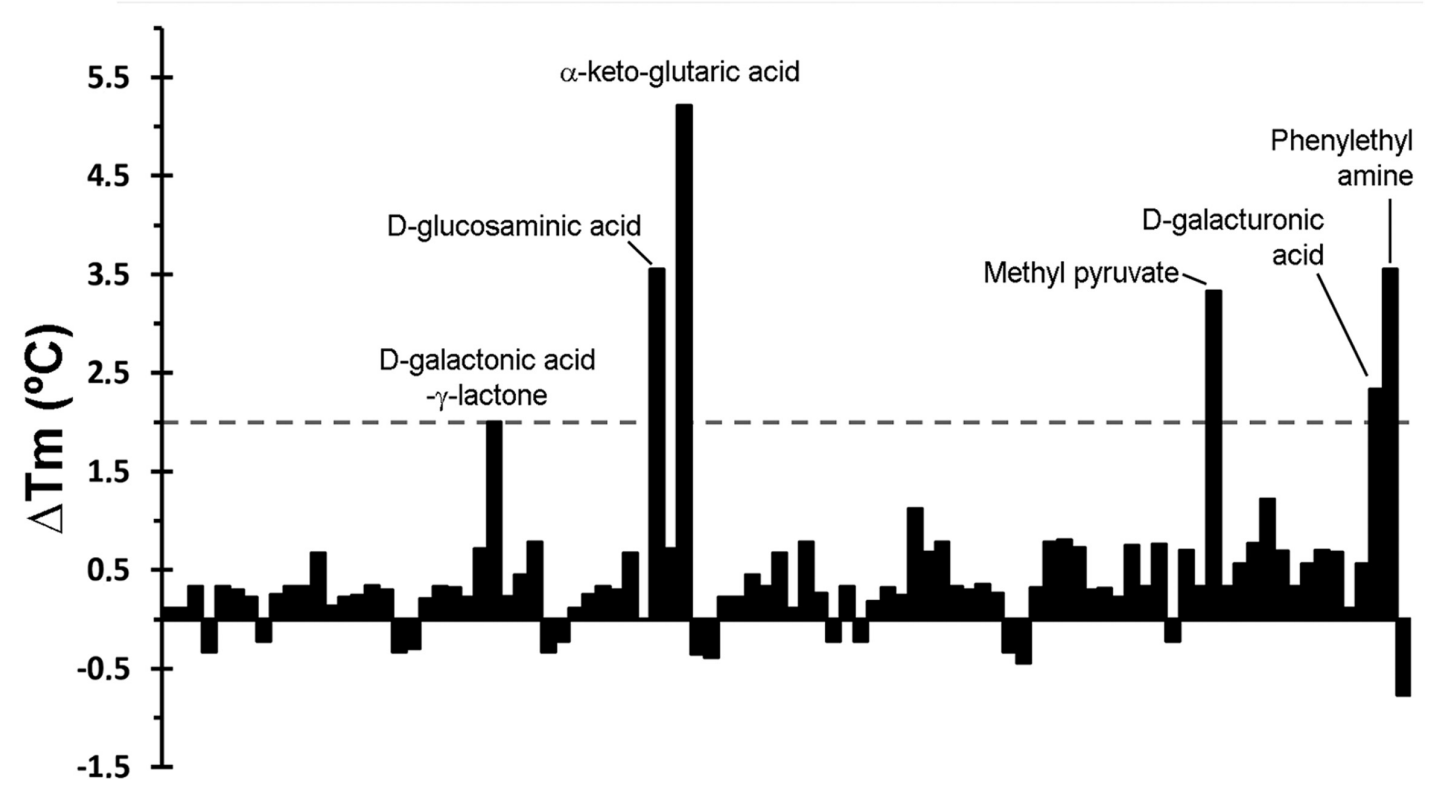

FIGURE 1 | Thermal shift assays of the recombinant ligand binding domain of the PA5072/McpK chemoreceptor in the presence of bacterial carbon sources from the Biolog screen plate PM1. Shown are changes in Tm respective to the protein without ligand $\left(38.7^{\circ} \mathrm{C}\right)$. A list of the individual compounds in this screen is provided in Supplementary Figure S1. Compounds that caused Tm shifts of at least $2^{\circ} \mathrm{C}$ are annotated.

E. coli and purified from the soluble fraction of the E. coli lysate.

To identify whether and which ligand bind may bind to this domain, we carried out thermal shift assays in high throughput screening format as reported by McKellar et al. (2015). In this assay, a temperature gradient is applied to a mixture of the purified protein and a fluorescent compound. During protein unfolding buried hydrophobic parts of the protein will be exposed leading to additional dye binding, causing fluorescent changes, which is the signal recorded. Consequently, this assay permits the calculation of the Tm value, which corresponds to the temperature at which half of the protein is in its native form and half is in the unfolded form (Krell, 2015). Ligand binding to a protein causes typically $\mathrm{Tm}$ changes, which gives useful initial information as to the identification of potential ligands. This assay has been essential to gain initial insight into the specificity of several chemoreceptors (McKellar et al., 2015; Corral-Lugo et al., 2016; Fernandez et al., 2016).

The thermal shift assays of ligand-free PA5072-LBD resulted in a $\mathrm{Tm}$ of $38.7^{\circ} \mathrm{C}$. Ligands tested included different bacterial carbon-, nitrogen-, phosphorous-, and sulfur sources as well as to nutrient supplements, which are listed in Supplementary Figure S1. As a representative example, the Tm changes induced by compounds of plate PM1 are shown in Figure 1. A total of 13 compounds were identified that increased or decreased the Tm by at least $2^{\circ} \mathrm{C}$ (Supplementary Table S2), which is the generally accepted threshold for a relevant ligand-induced change in protein stability. This analysis showed also that $\alpha$-ketoglutaric acid caused with $5.2^{\circ} \mathrm{C}$ the most pronounced $\mathrm{Tm}$ increase.

\section{$\alpha$-Ketoglutarate Binds With Positive Cooperativity to PA5072-LBD}

Thermal shift assays provide initial information on ligands that bind but represent no evidence of binding. A valid criterion to ascertain binding are isothermal titration calorimetry (ITC) (Krell, 2008) binding experiments. PA5072-LBD was titrated with all compounds that caused Tm changes of at least $2{ }^{\circ} \mathrm{C}$ (Supplementary Table S2). In these experiments $\alpha$-ketoglutarate $(\alpha K G)$ was the only compound that showed binding and the corresponding titration data are shown in Figure 2. The titration caused exothermic heat changes (down going peaks), but the biphasic titration curve indicates that the reaction is more complex than the binding of a ligand to a single site at a macromolecule. Data analysis was carried out with several models for the dependent or independent binding of ligands to multiple sites. A very satisfactory curve fit was obtained using a model for the cooperative binding of a molecule to two sites. The initial binding event was characterized by a $K_{\mathrm{d} 1}$ of $301.4 \pm 0.2 \mu \mathrm{M}(\Delta H 1=-0.16 \pm 0.05 \mathrm{kcal} / \mathrm{mol})$, whereas the second event had a $K_{\mathrm{d} 2}$ of $80.90 \pm 0.05 \mu \mathrm{M}$ $\left(\Delta H_{2}=-2.99 \pm 0.15 \mathrm{kcal} / \mathrm{mol}\right)$. The cooperativity factor $\mu$ was of 4.41 (with $\mu$ of 1 for a non-cooperative process), indicating an approximately fourfold increase in binding affinity of the second binding event as compared to the initial event. Alpha-KG binds thus with positive cooperativity to PA5072-LBD.

The criterion to establish that a given compound does not bind is the absence of binding heats in experiments conducted at two different analysis temperatures to exclude the possibility that exothermic and endothermic contributions to binding cancel out each other at a given analysis temperature. Therefore, binding of compounds that failed to bind at $20^{\circ} \mathrm{C}$ were also analyzed at $10^{\circ} \mathrm{C}$, 

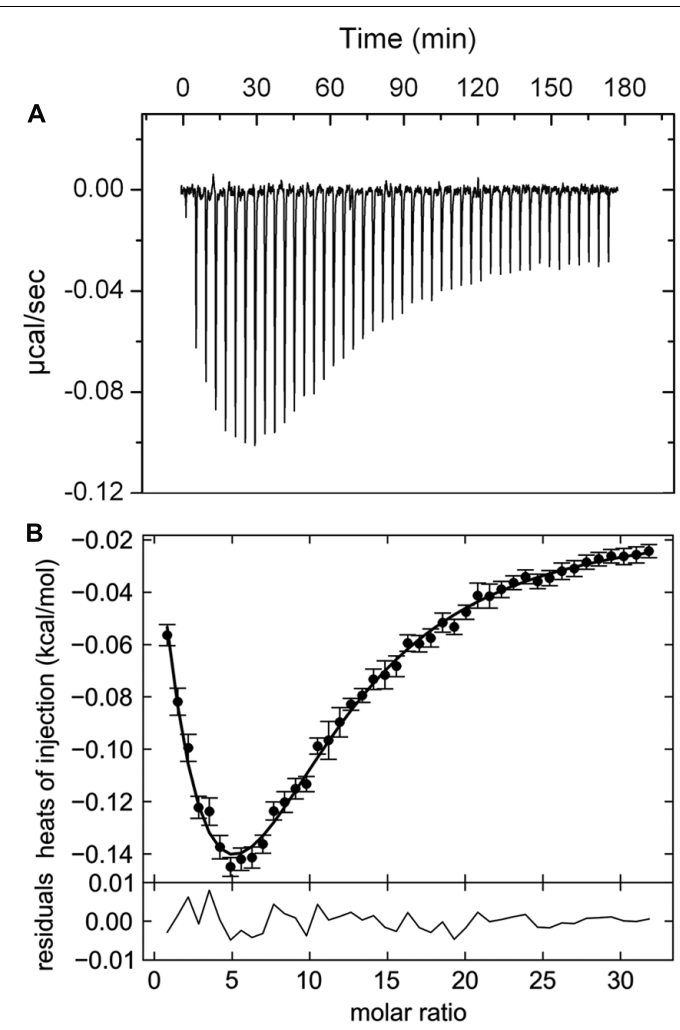

FIGURE 2 | Isothermal titration calorimetry data for the binding of $\alpha \mathrm{KG}$ to the ligand binding domain of the McpK chemoreceptor. (A) Heat changes caused by the injection of $3 \mathrm{mM} \alpha \mathrm{KG}$ into $20 \mu \mathrm{M}$ McpK-LBD. (B) Dilution heat-corrected and concentration-normalized integrated peak areas of raw data. The solid line shows the best fit with "the two symmetric-site binding model" of the SEDPHAT program. The residual of the curve fit are shown in the lower part of the figure.

which in all cases confirmed the absence of binding. As additional control experiment, $\alpha \mathrm{KG}$ was titrated into mixtures of protein with ligands that did not cause binding heats to verify protein integrity. In summary, of the compounds that caused significant Tm shifts, only $\alpha \mathrm{KG}$ was confirmed as PA5072 ligand.

We then explored by ITC whether other compounds that are structurally similar to $\alpha \mathrm{KG}$ may bind to PA5072-LBD and the 15 ligands selected for further ITC studies are provided in Supplementary Table S2. In analogy to the above results, we were unable to detect any binding and concluded that PA5072 binds exclusively $\alpha$ KG. The receptor was therefore named McpK (methyl-accepting chemotaxis protein $\mathrm{K}$ ).

\section{McpK-LBD Dimer Stabilization by $\alpha$ KG Binding}

The unexpected observation of binding with positive cooperativity indicates the presence of higher oligomeric states of the protein analyzed. To assess this issue, we carried out analytical ultracentrifugation (AUC) studies of McpK-LBD in the absence and presence of $\alpha \mathrm{KG}$. Initial SM studies of ligand free protein revealed two species with standard sedimentation coefficients of $s_{20, w}=2.45 \mathrm{~S}$ and $s_{20, w}=3.18 \mathrm{~S}$ (Figure 3; note:

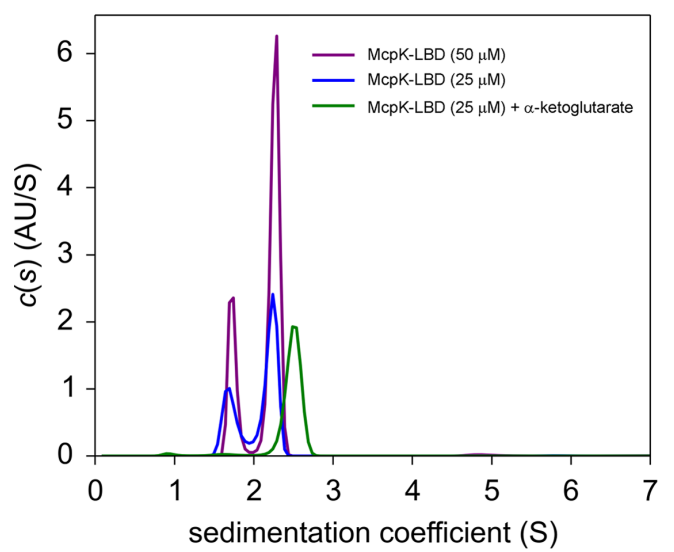

FIGURE 3 | Determination of the oligomeric state of McpK-LBD by sedimentation velocity analytical ultracentrifugation. Shown are sedimentation coefficient distributions of McpK-LBD in the absence and presence of $1 \mathrm{mM} \alpha$-ketoglutarate.

these values are standard values normalized for migration in water, whereas Figure 3 shows the experimental data recorded in buffer). The frictional ratio ( $f r$ ) for the peak at $2.45 \mathrm{~S}$ is 1.5 , indicative of a rather elongated protein morphology, which agrees with the structure of HBM domains (Pineda-Molina et al., 2012; Ortega and Krell, 2014). Based on this frictional ratio and using the diffusional scaling law of SEDFIT and the Svedberg equation, the average molar mass of the protein was determined $31.1 \mathrm{kDa}$, which is very close to the sequence-derived mass of the monomer $(30.5 \mathrm{kDa})$. The peak of the fast sedimenting species $\left(s_{20, w}=3.18 \mathrm{~S}\right)$ shows a similar $\mathrm{fr}$ corresponding to an elongated particle. The molar mass extracted was $45.8 \mathrm{kDa}$, which may point to a virtual intermediate species resulting from the fast equilibrium between the monomers and dimers. Such virtual species have been observed previously for the analysis of the homologous domain of the P. putida KT2440 McpQ chemoreceptor (Martin-Mora et al., 2016). When the experiment was conducted in the presence of $1 \mathrm{mM} \alpha \mathrm{KG}$ a single peak with $s_{20, w}=3.58 \mathrm{~S}$ was observed that translates to a species with a molecular mass of $58.7 \mathrm{kDa}$, close to the sequence derived mass of the protein dimer $(61 \mathrm{kDa})$.

The self-association behavior observed by SM was further demonstrated by multi-speed SE experiments. The SE of McpK at three different concentrations was analyzed by a global fit that confirmed the presence of both the monomeric and dimeric species at all concentrations (Figure 4). For ligandfree McpK-LBD a dimer self-dissociation constant of $55.0 \mu \mathrm{M}$ could be determined. When this experiment was repeated in the presence of $1 \mathrm{mM} \alpha \mathrm{KG}$, a tighter association was observed, with an approximately 10 -fold lower self-dissociation constant of $5.9 \mu \mathrm{M}$, confirming that $\alpha \mathrm{KG}$ causes McpK-LBD dimer stabilization.

At the protein concentration used for ITC binding studies, McpK-LBD is thus partially present as dimer and the cooperativity observed is thus likely due to ligand binding to the different monomers of the dimer in a way that the initial 

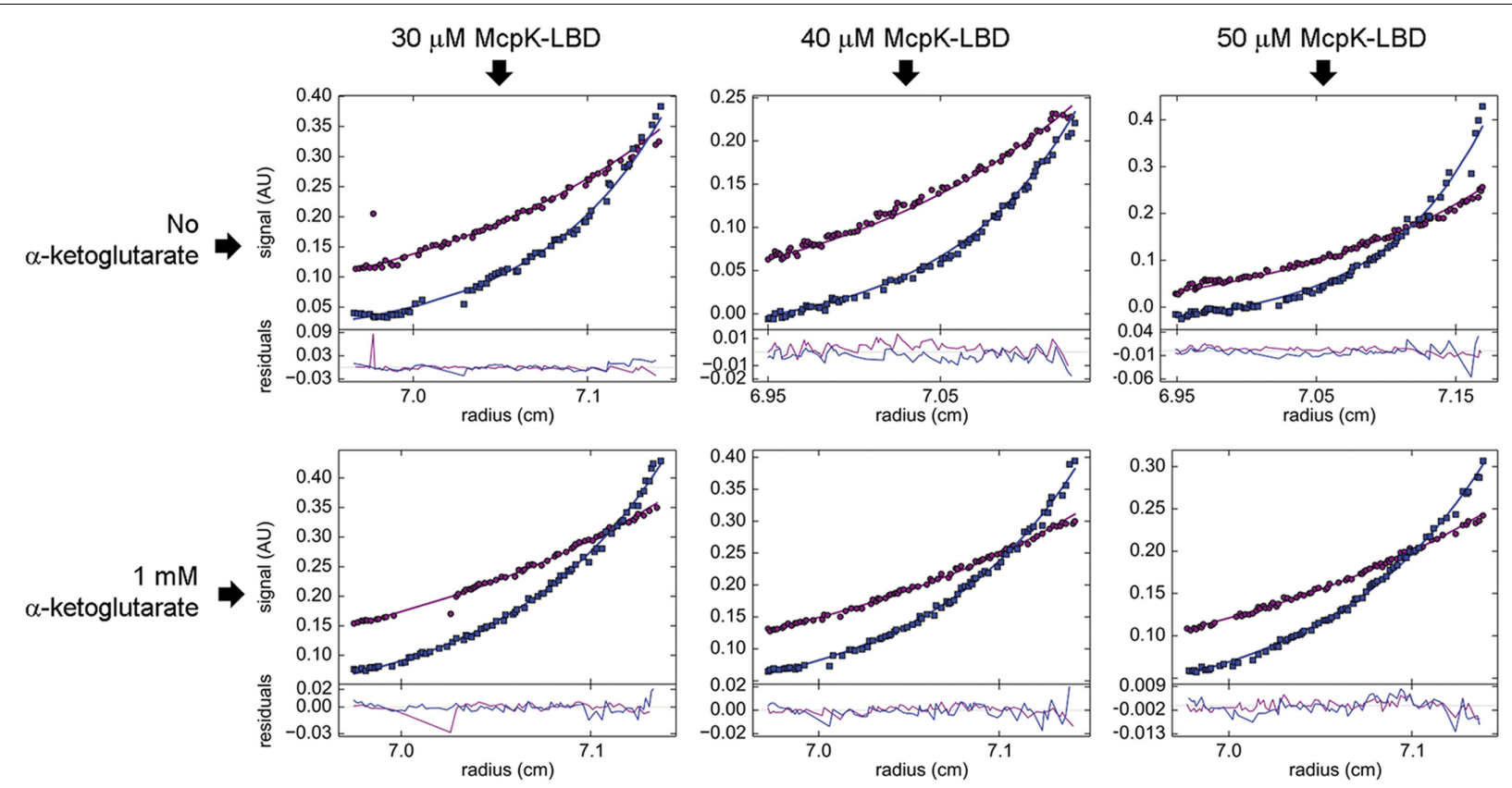

FIGURE 4 | Study of McpK-LBD dimer association by sedimentation equilibrium analytical ultracentrifugation. Sedimentation equilibrium profiles of McpK-LBD at a speed of 9,740 (purple) and 20,606 $\times g$ (blue), at three different protein concentrations and in the absence and presence of 1 mM aKG. The best global fit is shown as a continuous line for both speeds along with the residuals of fitting in the lower part of the figure.

binding to one monomer of the dimer enhances the affinity for the second monomer.

\section{McpK Mediates Chemotaxis to $\alpha \mathrm{KG}$}

Chemoreceptors can either mediate chemotaxis, have alternative cellular functions or are responsible for type IV pili mediated motility (Wuichet and Zhulin, 2010). To determine McpK function, we generated a $m c p K$ deletion mutant and carried out quantitative capillary chemotaxis assays. Initially, control experiments were conducted to assess chemotaxis of the wt and mutant strain toward casamino acids. The choice of this chemoattractant was based on the fact that the chemotaxis toward amino acids is mediated by the three well-characterized chemoreceptors PctA, PctB and PctC (Taguchi et al., 1997; Rico-Jimenez et al., 2013). As shown in Supplementary Figure S3, deletion of $m c p K$ did not alter significantly chemotaxis to casamino acids, indicating that this mutation did not cause any general motility defect.

Subsequently, chemotaxis assays toward different $\alpha \mathrm{KG}$ concentrations were performed. Experiments showed that the wt strain has significant taxis to $\alpha \mathrm{KG}$ concentrations between $5 \mu \mathrm{M}$ and $5 \mathrm{mM}$, with an optimal response at $500 \mu \mathrm{M}$ (Figure 5). Importantly, the deletion of the $m c p K$ gene resulted in a drop in the chemotactic response to close to baseline levels. Complementation of this mutant by the in trans expression of the $m c p K$ gene restored wild type like chemotaxis at all concentrations (Figure 5). In order to determine whether the observed chemotaxis defect in the $m c p K$ mutant is the result of an altered metabolism, we performed growth curves in M9 minimal medium supplemented with $\alpha \mathrm{KG}$ and succinate as carbon sources. As shown in Supplementary Figure S4, there were no differences between the wt and mutant strain. Taken together, these data show that McpK is the primary chemoreceptor for $\alpha \mathrm{KG}$ in $P$. aeruginosa PAO1.

\section{$\alpha$-Ketoglutarate Does Not Regulate mcpK Expression}

We have recently assessed the effect of chemoeffectors on the gene expression of their cognate chemoreceptors in P. putida KT2440 (López-Farfán et al., 2016). We were able to show that the expression of a significant number of chemoreceptor genes is either up- or downregulated by the cognate chemoeffectors. However, this was not the case for genes encoding chemoreceptors that respond to TCA cycle intermediates, namely $m c p S, m c p Q$ and $m c p R$ that were expressed independently of the presence or absence of their cognate ligands.

To assess $m c p K$ expression, we carried out real-time quantitative PCR measurements. Figure 6A shows $m c p K$ transcript levels of samples taken during mid-exponential phase in comparison to those of the housekeeping genes gyrB and $r p o D$ as well as to genes encoding functionally characterized chemoreceptors such as the amino acid sensors PctA and PctC (Taguchi et al., 1997), the Pi responsive CtpH (Wu et al., 2000) or the TlpQ chemoreceptor that mediates taxis to ethylene (Kim et al., 2007). Data show that $m c p K$ transcript levels are low as compared to the housekeeping genes and in between most and less abundant chemoreceptor transcripts.

In subsequent experiments we assessed the effect of $\alpha \mathrm{KG}$ on $m c p K$ expression. However, the addition of $\alpha \mathrm{KG}$ to $P$. aeruginosa cultures grown in M9 minimal medium supplemented with 


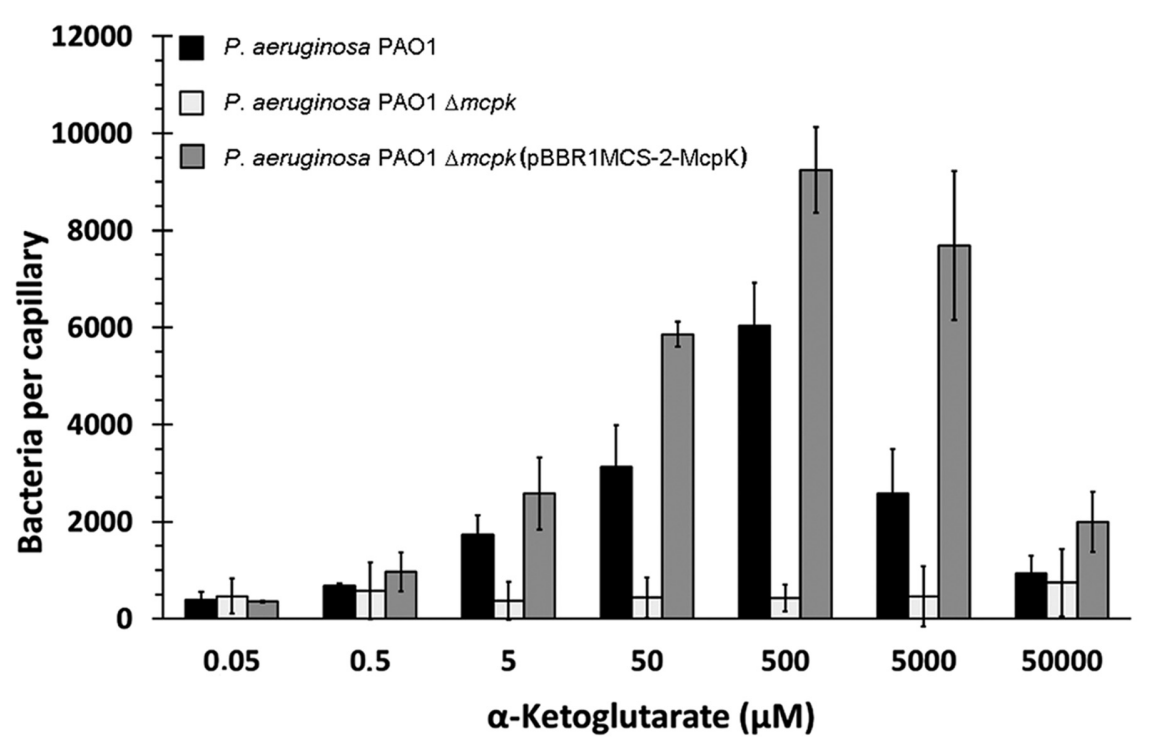

FIGURE 5 | The effect of McpK on $\alpha$-ketoglutarate chemotaxis. Quantitative capillary chemotaxis assays of $P$. aeruginosa PAO1, $P$. aeruginosa $\Delta m c p K$ and the complemented mutant $P$. aeruginosa $\Delta m c p K$ (pBBR1MCS-2-McpK) toward different $\alpha K G$ concentrations. Data were corrected with the number of cells that swam into buffer-containing capillaries (833 \pm 106$)$. Shown are means and standard errors from three independent experiments, each conducted in triplicate.

glucose did not alter $m c p K$ expression (Figure 6B). Data thus show that, in analogy to the TCA cycle intermediate responsive chemoreceptors in P. putida KT2440, the cognate chemoeffector $\alpha \mathrm{KG}$ does not modulate $m c p K$ expression. Further experiments will show whether the constitutive expression of TCA cycle intermediate responsive chemoreceptors, as observed in P. putida and $P$. aeruginosa, is a general feature.

\section{McpK Mediated Chemotaxis Does Not Affect Plant Root Colonization}

Pseudomonas aeruginosa is a universal pathogen that is also able to colonize and infect different plants (Rahme et al., 2000; Cao et al., 2001; Walker et al., 2004; Attila et al., 2008). The web-based resource PIFAR allowed the identification of 175 gene products in $P$. aeruginosa putatively involved in the interaction with plants (Martinez-Garcia et al., 2016) and the TlpQ chemoreceptor was found to mediate chemotaxis toward the plant hormone ethylene (Kim et al., 2007). $\alpha \mathrm{KG}$ is present at significant levels in plant root exudates (Tawaraya et al., 2014; Ganie et al., 2015) and chemotaxis to root exudate components was shown to be essential for efficient root colonization (de Weert et al., 2002; Scharf et al., 2016).

To determine the role of $\mathrm{McpK}$ in the colonization of the rhizosphere, we performed competitive colonization assays using maize as model plant. Initial experiments showed that $P$. aeruginosa colonizes the maize rhizosphere at a density of around $5 \times 10^{7}$ bacteria per gram of root. To distinguish between the wild type and the mutant strain, a kanamycinresistant $P$. aeruginosa wild type strain was generated. This strain contains a kanamycin cassette inserted downstream of the glucosamine-6-phosphate synthetase encoding gene, glmS. This region was demonstrated to be neutral in multiple Pseudomonas strains, including $P$. aeruginosa (Koch et al., 2001; Matilla et al., 2007). The resulting strain, $P$. aeruginosa PAO1-Km, was shown to mediate chemotaxis to $\alpha \mathrm{KG}$ (and other known chemoattractants) at the same levels as PAO1 (Supplementary Figure S5). Competitive colonization assays showed that the fitness of the mutant in $m c p K$ in the rhizosphere was similar to the strain PAO1-Km (Figure 7). Additionally, the strain $\Delta m c p K$ also colonized root tips at the wild type levels (Figure 7).

\section{DISCUSSION}

Chemoreceptors can be classified according to their ligand spectrum into receptors that recognize various, structurally related chemoeffectors and those that appear to be specific for a single chemoeffector. Examples of the former group are receptors for different L-amino acids (Taguchi et al., 1997; Glekas et al., 2012; Oku et al., 2012; Brennan et al., 2013; Rico-Jimenez et al., 2013; Webb et al., 2016), cyclic organic acids (Luu et al., 2015), purines (Fernandez et al., 2016), polyamines (Corral-Lugo et al., 2016), aromatic hydrocarbons (Lacal et al., 2011b), C4C6 organic acids (Lacal et al., 2010a; Parales et al., 2013) or C2- and C3-organic acids (Garcia et al., 2015). Chemoreceptors that appear to respond to a single compound include the citrate specific chemoreceptors Tcp of Salmonella typhimurium (Yamamoto and Imae, 1993) and McpQ of P. putida KT2440 (Martin-Mora et al., 2016), the malate specific receptor PA2652 in P. aeruginosa or the GABA specific McpG of P. putida KT2440 (Reyes-Darias et al., 2015a). Here we report with McpK another chemoreceptor that binds specifically a single compound, $\alpha \mathrm{KG}$. Interestingly, the ligands of these specific chemoreceptors are either part of or closely linked to the TCA cycle (note: GABA is part of the GABA shunt converting $\alpha \mathrm{KG}$ into succinate). 

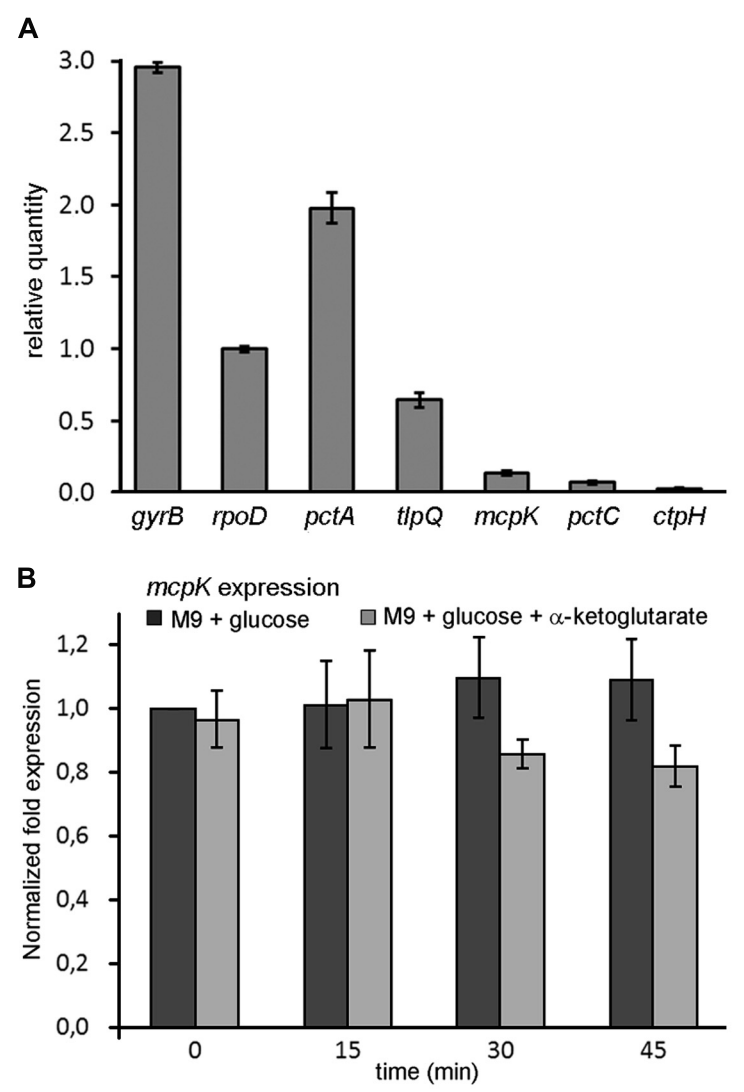

FIGURE 6 | Expression of the mcpK gene in the absence and presence of $\alpha$-ketoglutarate. (A) RT-qPCR measurements of the relative transcript levels of $P$. aeruginosa $m c p K$, pctA, t/pQ, pctC and ctpH chemoreceptor genes as well as of the housekeeping genes gyrB and rpoD. Cells were grown in M9 minimal medium supplemented with $10 \mathrm{mM}$ glucose and samples taken at mid-exponential phase. (B) Gene expression of $m c p K$ in the absence and presence of $1 \mathrm{mM} \alpha \mathrm{KG}$. Cells were grown to mid-exponential phase in $\mathrm{M} 9$ supplemented with $10 \mathrm{mM}$ glucose and samples were taken after 0, 15, 30, and $45 \mathrm{~min}$. The results are expressed as the relative expression of $\mathrm{mcpK}$ normalized with the transcript level of the reference gene rpo $D$ at time 0 in the absence of $\alpha K G$. Data shown are the average of two independent experiments.

The evolution of specific chemoreceptors suggests that these compounds are of importance to the microorganism. The existence of a chemoreceptor dedicated to $\alpha \mathrm{KG}$ may be linked to the central metabolic role of this compound (Figure 8). Apart from being part of the TCA cycle, $\alpha \mathrm{KG}$ also represents a branch point from which other important metabolic pathways depart such as the GABA shunt, biosynthetic pathways for several amino acids and coenzyme $B$ or the purine and pyrimidine synthesis.

Several important chemoattractants have a dual function and exert metabolic as well as signaling roles. Examples are GABA, the only ligand of $P$. putida KT2440 McpG (Reyes-Darias et al., 2015a), and putrescine, the high-affinity ligand of McpU of the same species (Corral-Lugo et al., 2016). Both compounds serve as carbon and nitrogen sources and also exert functions as signaling molecules. Alpha-KG belongs to the same class of compound. Apart from being a carbon source it was shown to modulate the

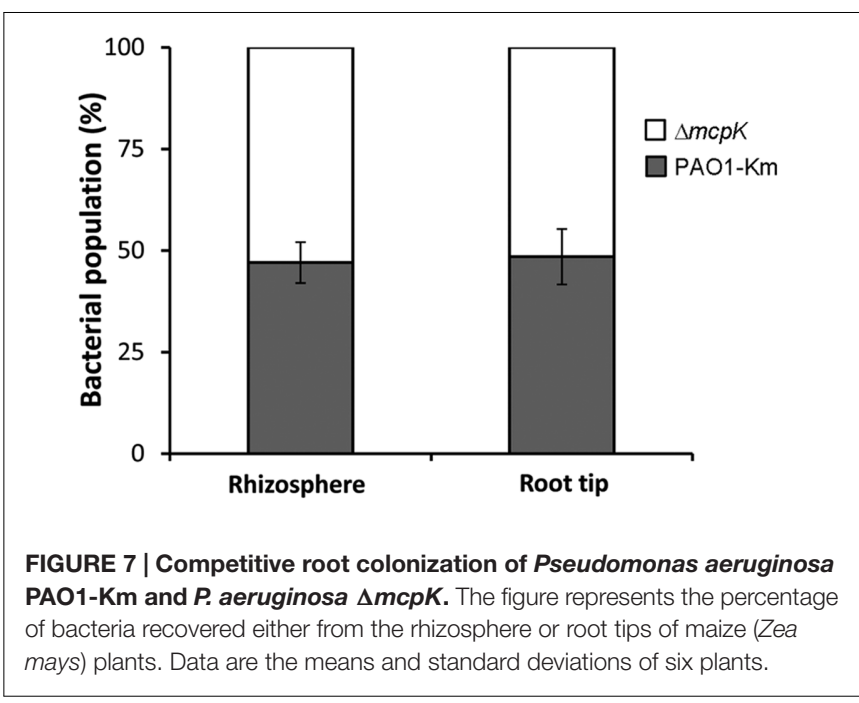

activity of the NtrB/NtrC two component system (TCS) for the control of nitrogen utilization processes ( $\mathrm{Li}$ and $\mathrm{Lu}, 2007$ ). The activity of this TCS is regulated by the small protein PII that senses $\alpha K G$ as carbon signal and glutamine as nitrogen signals (Ninfa and Jiang, 2005). In addition, a model was proposed in which $\alpha$ KG regulates in $P$. aeruginosa the activity of another TCS, namely the MifS/MifR system, which regulates genes that are involved in $\alpha \mathrm{KG}$ transport and subsequent metabolism (Tatke et al., 2015).

In contrast to the dCACHE domain that recognizes ligands in the monomeric state (Rico-Jimenez et al., 2013), the HBM and 4-helix bundle domain need to be dimeric for ligand recognition (Milburn et al., 1991; Lacal et al., 2010a; Martin-Mora et al., 2016). This is due to the fact that the ligand binding sites are at the dimer interface and that amino acids from both monomers of the dimer are involved in ligand binding (Milburn et al., 1991; PinedaMolina et al., 2012). Tsr (Lin et al., 1994) and Tar (Milligan and Koshland, 1993; Biemann and Koshland, 1994; Danielson et al., 1994) that both contain a 4-helix bundle domain, bind serine and aspartate, respectively, with a 1 per dimer stoichiometry, which is due to an extreme form of negative cooperativity in which ligand binding to the first monomer causes a dramatic reduction of affinity for the second monomer of the dimer. This negative cooperativity has been observed for the full-length receptor (Biemann and Koshland, 1994; Lin et al., 1994) as well as for the individual, recombinant LBDs (Milligan and Koshland, 1993; Danielson et al., 1994). In marked contrast, McpK-LBD bound its ligand with positive cooperativity. In contrast to the very strong negative cooperativity observed for Tar and Tsr, the positive cooperativity at McpK-LBD was more modest and ligand binding at the first monomer increased affinity of the second ligand by approximately fourfold. To our knowledge, this is the first report on a chemoreceptor-LBD that recognizes its ligands in positively cooperative manner. The evolution of a receptor with positive cooperativity may be straightforward, since it was shown that the mutation of a single amino acid at the dimer interface of Tar converts its negative cooperativity into positive cooperativity (Kolodziej et al., 1996). Further experiments will 


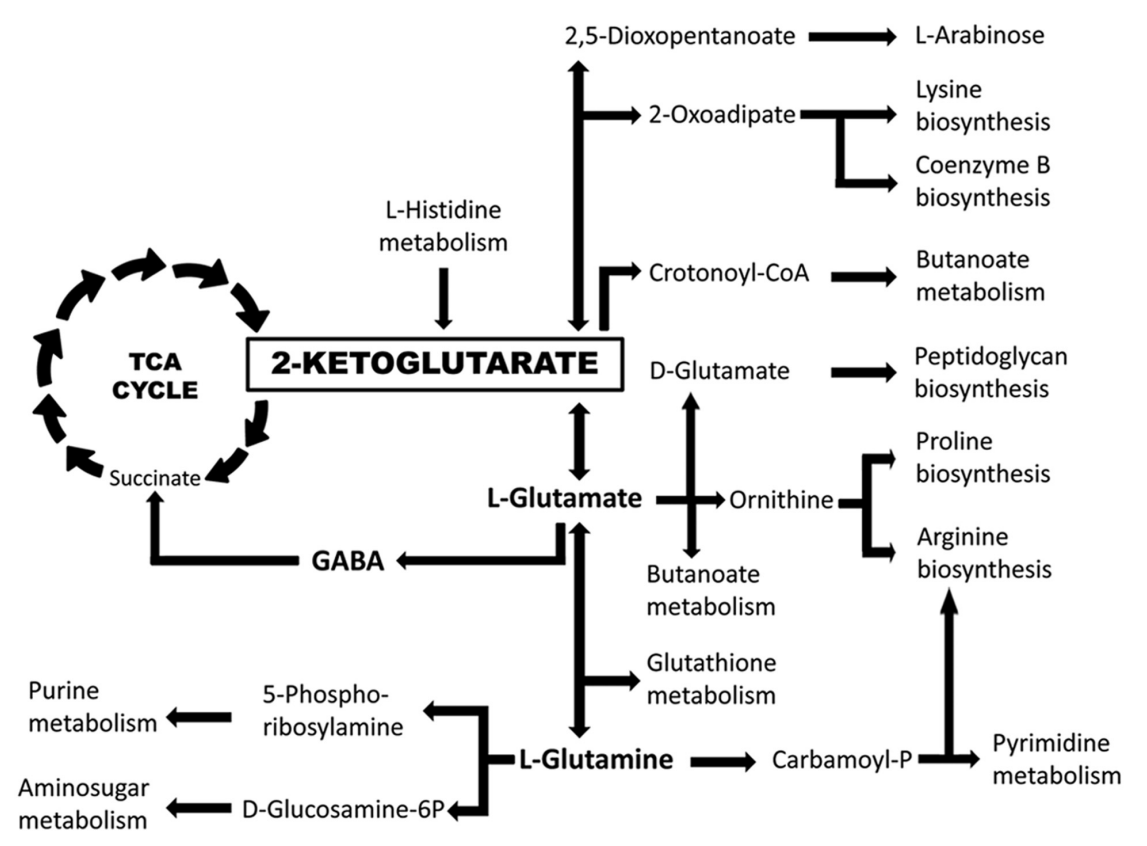

FIGURE 8 | The central role of $\alpha$ KG in the metabolism of $\boldsymbol{P}$. aeruginosa PAO1. Implication of $\alpha$ KG in key metabolic pathways as derived from the KEGG (Kanehisa et al., 2016) map of $P$. aeruginosa PAO1.

provide insight as to the functional or physiological reasons for ligand recognition with positive cooperativity.

Analytical ultracentrifugation studies show that $\alpha \mathrm{KG}$ binding stabilizes the dimer. Equilibrium studies showed that $\alpha \mathrm{KG}$ binding reduces the dimer self-dissociation constant from 55 to $5.9 \mu \mathrm{M}$. Chemoeffector mediated LBD dimer stabilization appears to be a general feature of 4-helix bundle and HBM domains since similar observations have been made for Tar-LBD (Milligan and Koshland, 1993; Yu et al., 2015), McpQ (MartinMora et al., 2016), McpS (Lacal et al., 2010a).

The expression of the genes of a significant number of $P$. putida chemoreceptors is modulated by their cognate ligands (López-Farfán et al., 2016). However, exceptions were the TCA cycle intermediate responsive chemoreceptor genes that are expressed constitutively. It was hypothesized that the omnipresence in natural habitats and metabolic importance of TCA cycle intermediates may be responsible for this constitutive expression (López-Farfán et al., 2016). The present finding that $\alpha \mathrm{KG}$ does not modulate $m c p K$ expression provides further support to this hypothesis.

Chemotaxis to plant root exudates was shown to promote bacterial colonization (de Weert et al., 2002; Reyes-Darias et al., 2015a; Scharf et al., 2016). However, the deletion of the $m c p K$ gene did not cause any significant differences in maize root colonization. Root exudates are complex mixtures of mainly sugars, amino acids and organic acids. A significant part of $P$. aeruginosa chemoreceptors are likely to respond to exudate components (like PctA, PctB and PctC) and therefore the effects caused by the elimination of a single chemoreceptor is compensated by other root exudate responsive receptors. We have shown that the elimination of the GABA specific McpG receptor did reduce root colonization (Reyes-Darias et al., 2015a). However, GABA recognition at McpG-LBD $\left(K_{\mathrm{D}}=175 \mathrm{nM}\right)$ was much tighter than $\alpha$ KG binding to McpK-LBD $\left(K_{\mathrm{d} 1}=301 \mu \mathrm{M}\right.$, $\left.K_{\mathrm{d} 2}=81 \mu \mathrm{M}\right)$.

Chemoreceptors contain a variety of different LBD types (Lacal et al., 2010b; Upadhyay et al., 2016) and a central question in understanding this diversity is to elucidate whether there is a relationship between the LBD type and the structure of the chemoeffector recognized. In this aspect first tendencies have appeared and it was suggested that sCACHE domains may be linked to the recognition of $\mathrm{C} 2$ - and $\mathrm{C} 3$-carboxylic acids (Garcia et al., 2015), whereas the dCACHE domain may be the dominant domain for the recognition of L-amino acids (Glekas et al., 2012; Oku et al., 2012; Liu et al., 2015; ReyesDarias et al., 2015b). The alignment of all members of the HBM domain family revealed the conservation of amino acids of the ligand binding cavity (Ortega and Krell, 2014). Since C4 to C6 organic acids were found to bind to the first characterized member of this family, McpS, it was proposed that the HBM domain may be associated with the recognition of organic acids (Ortega and Krell, 2014). This hypothesis was supported by the identification of other HBM domain containing chemoreceptors that mediate taxis to this class of compound such as the citrate specific McpQ as well as McfS/McfQ (Parales et al., 2013) and Pfl01_0728 that all respond to organic acids (Oku et al., 2014). The identification of McpK as another HBM family member that binds to an organic acid lends further support to this hypothesis. Establishing LBD type - chemoeffector relationships will permit to orient experiments to a certain group of compounds, which in turn will accelerate the functional annotation of receptors. 


\section{AUTHOR CONTRIBUTIONS}

DM-M, AO, JR-D, VG, and DL-F designed experiments, conducted experiments and analyzed data; MM conducted research, analyzed data and wrote the manuscript; TK designed experiments, analyzed data and wrote the manuscript.

\section{ACKNOWLEDGMENTS}

We acknowledge financial support from FEDER funds and Fondo Social Europeo through grants from the Junta de

\section{REFERENCES}

Airola, M. V., Huh, D., Sukomon, N., Widom, J., Sircar, R., Borbat, P. P., et al. (2013). Architecture of the soluble receptor Aer2 indicates an in-line mechanism for PAS and HAMP domain signaling. J. Mol. Biol. 425, 886-901. doi: 10.1016/j.jmb.2012.12.011

Alvarez-Ortega, C., and Harwood, C. S. (2007). Identification of a malate chemoreceptor in Pseudomonas aeruginosa by screening for chemotaxis defects in an energy taxis-deficient mutant. Appl. Environ. Microbiol. 73, 7793-7795. doi: 10.1128/AEM.01898-07

Attila, C., Ueda, A., Cirillo, S. L., Cirillo, J. D., Chen, W., and Wood, T. K. (2008). Pseudomonas aeruginosa PAO1 virulence factors and poplar tree response in the rhizosphere. Microb. Biotechnol. 1, 17-29. doi: 10.1111/j.1751-7915.2007. 00002.x

Biemann, H. P., and Koshland, D. E. Jr. (1994). Aspartate receptors of Escherichia coli and Salmonella typhimurium bind ligand with negative and half-of-the-sites cooperativity. Biochemistry 33, 629-634. doi: 10.1021/bi00169a002

Boyer, H. W., and Roulland-Dussoix, D. (1969). A complementation analysis of the restriction and modification of DNA in Escherichia coli. J. Mol. Biol. 41, 459-472. doi: 10.1016/0022-2836(69)90288-5

Brennan, C. A., Deloney-Marino, C. R., and Mandel, M. J. (2013). Chemoreceptor VfcA mediates amino acid chemotaxis in Vibrio fischeri. Appl. Environ. Microbiol. 79, 1889-1896. doi: 10.1128/AEM.03794-12

Cao, H., Baldini, R. L., and Rahme, L. G. (2001). Common mechanisms for pathogens of plants and animals. Annu. Rev. Phytopathol. 39, 259-284. doi: 10.1146/annurev.phyto.39.1.259

Corral-Lugo, A., De La Torre, J., Matilla, M. A., Fernandez, M., Morel, B., EspinosaUrgel, M., et al. (2016). Assessment of the contribution of chemoreceptor-based signaling to biofilm formation. Environ. Microbiol. 18, 3355-3372. doi: 10.1111/ 1462-2920.13170

Cserzo, M., Wallin, E., Simon, I., Von Heijne, G., and Elofsson, A. (1997). Prediction of transmembrane alpha-helices in prokaryotic membrane proteins: the dense alignment surface method. Protein Eng. 10, 673-676. doi: 10.1093/ protein/10.6.673

Danielson, M. A., Biemann, H. P., Koshland, D. E. Jr., and Falke, J. J. (1994). Attractant- and disulfide-induced conformational changes in the ligand binding domain of the chemotaxis aspartate receptor: a 19F NMR study. Biochemistry 33, 6100-6109. doi: 10.1021/bi00186a009

de Lorenzo, V., Herrero, M., Jakubzik, U., and Timmis, K. N. (1990). MiniTn5 transposon derivatives for insertion mutagenesis, promoter probing, and chromosomal insertion of cloned DNA in gram-negative eubacteria. J. Bacteriol. 172, 6568-6572. doi: 10.1128/jb.172.11.6568-6572.1990

de Weert, S., Vermeiren, H., Mulders, I. H., Kuiper, I., Hendrickx, N., Bloemberg, G. V., et al. (2002). Flagella-driven chemotaxis towards exudate components is an important trait for tomato root colonization by Pseudomonas fluorescens. Mol. Plant Microbe Interact. 15, 1173-1180. doi: 10.1094/MPMI.2002.15.11. 1173

Dennis, J. J., and Zylstra, G. J. (1998). Plasposons: modular self-cloning minitransposon derivatives for rapid genetic analysis of gram-negative bacterial genomes. Appl. Environ. Microbiol. 64, 2710-2715.
Andalucía (grant CVI-7335) and the Spanish Ministry for Economy and Competitiveness (grant BIO2013-42297). MM was supported by the Spanish Ministry of Economy and Competitiveness Postdoctoral Research Program, Juan de la Cierva (JCI-2012-11815).

\section{SUPPLEMENTARY MATERIAL}

The Supplementary Material for this article can be found online at: http://journal.frontiersin.org/article/10.3389/fmicb. 2016.01937/full\#supplementary-material

Dorotkiewicz-Jach, A., Augustyniak, D., Olszak, T., and Drulis-Kawa, Z. (2015). Modern therapeutic approaches against Pseudomonas aeruginosa infections. Curr. Med. Chem. 22, 1642-1664. doi: 10.2174/0929867322666150417122531

Erhardt, M. (2016). Strategies to block bacterial pathogenesis by interference with motility and chemotaxis. Curr. Top Microbiol. Immunol. doi: 10.1007/82 _2016_493 [Epub ahead of print].

Fernandez, M., Morel, B., Corral-Lugo, A., and Krell, T. (2016). Identification of a chemoreceptor that specifically mediates chemotaxis toward metabolizable purine derivatives. Mol. Microbiol. 99, 34-42. doi: 10.1111/mmi.13215

Ganie, A. H., Ahmad, A., Pandey, R., Aref, I. M., Yousuf, P. Y., Ahmad, S., et al. (2015). Metabolite profiling of low-P tolerant and low-P sensitive maize genotypes under phosphorus starvation and restoration conditions. PLOS ONE 10:e0129520. doi: 10.1371/journal.pone.0129520

Garcia, D., Watts, K. J., Johnson, M. S., and Taylor, B. L. (2016). Delineating PASHAMP interaction surfaces and signalling-associated changes in the aerotaxis receptor Aer. Mol. Microbiol. 100, 156-172. doi: 10.1111/mmi.13308

Garcia, V., Reyes-Darias, J. A., Martin-Mora, D., Morel, B., Matilla, M. A., and Krell, T. (2015). Identification of a chemoreceptor for C2- and C3-carboxylic acids. Appl. Environ. Microbiol. 81, 5449-5457. doi: 10.1128/AEM.01529-15

Garcia-Fontana, C., Corral Lugo, A., and Krell, T. (2014). Specificity of the CheR2 methyltransferase in Pseudomonas aeruginosa is directed by a C-terminal pentapeptide in the McpB chemoreceptor. Sci. Signal. 7, ra34. doi: 10.1126/ scisignal.2004849

Garvis, S., Munder, A., Ball, G., De Bentzmann, S., Wiehlmann, L., Ewbank, J. J., et al. (2009). Caenorhabditis elegans semi-automated liquid screen reveals a specialized role for the chemotaxis gene cheB2 in Pseudomonas aeruginosa virulence. PLoS Pathog 5:e1000540. doi: 10.1371/journal.ppat.1000540

Gellatly, S. L., and Hancock, R. E. (2013). Pseudomonas aeruginosa: new insights into pathogenesis and host defenses. Pathog. Dis. 67, 159-173. doi: 10.1111/ 2049-632X.12033

Glekas, G. D., Mulhern, B. J., Kroc, A., Duelfer, K. A., Lei, V., Rao, C. V., et al. (2012). The Bacillus subtilis chemoreceptor McpC senses multiple ligands using two discrete mechanisms. J. Biol. Chem. 287, 39412-39418. doi: 10.1074/jbc. M112.413518

Hazelbauer, G. L., Falke, J. J., and Parkinson, J. S. (2008). Bacterial chemoreceptors: high-performance signaling in networked arrays. Trends Biochem. Sci. 33, 9-19. doi: 10.1016/j.tibs.2007.09.014

Herrero, M., de Lorenzo, V., and Timmis, K. N. (1990). Transposon vectors containing non-antibiotic resistance selection markers for cloning and stable chromosomal insertion of foreign genes in gram-negative bacteria. J. Bacteriol. 172, 6557-6567. doi: 10.1128/jb.172.11.6557-6567.1990

Hickman, J. W., Tifrea, D. F., and Harwood, C. S. (2005). A chemosensory system that regulates biofilm formation through modulation of cyclic diguanylate levels. Proc. Natl. Acad. Sci. U.S.A. 102, 14422-14427. doi: 10.1073/ pnas.0507170102

Houtman, J. C., Brown, P. H., Bowden, B., Yamaguchi, H., Appella, E., Samelson, L. E., et al. (2007). Studying multisite binary and ternary protein interactions by global analysis of isothermal titration calorimetry data in SEDPHAT: application to adaptor protein complexes in cell signaling. Protein Sci. 16, 30-42. doi: 10.1110/ps.062558507 
Jeong, H., Barbe, V., Lee, C. H., Vallenet, D., Yu, D. S., Choi, S. H., et al. (2009). Genome sequences of Escherichia coli B strains REL606 and BL21(DE3). J. Mol. Biol. 394, 644-652. doi: 10.1016/j.jmb.2009.09.052

Juhas, M. (2015). Pseudomonas aeruginosa essentials: an update on investigation of essential genes. Microbiology 161, 2053-2060. doi: 10.1099/mic.0.000161

Kamath, K. S., Pascovici, D., Penesyan, A., Goel, A., Venkatakrishnan, V., Paulsen, I. T., et al. (2016). Pseudomonas aeruginosa cell membrane protein expression from phenotypically diverse cystic fibrosis isolates demonstrates host-specific adaptations. J. Proteome Res. 15, 2152-2163. doi: 10.1021/acs. jproteome.6b00058

Kanehisa, M., Sato, Y., Kawashima, M., Furumichi, M., and Tanabe, M. (2016). KEGG as a reference resource for gene and protein annotation. Nucleic Acids Res. 44, D457-D462. doi: 10.1093/nar/gkv1070

Kaniga, K., Delor, I., and Cornelis, G. R. (1991). A wide-host-range suicide vector for improving reverse genetics in gram-negative bacteria: inactivation of the blaA gene of Yersinia enterocolitica. Gene 109, 137-141. doi: 10.1016/03781119(91)90599-7

Kato, J., Kim, H. E., Takiguchi, N., Kuroda, A., and Ohtake, H. (2008). Pseudomonas aeruginosa as a model microorganism for investigation of chemotactic behaviors in ecosystem. J. Biosci. Bioeng. 106, 1-7. doi: 10.1263/jbb.106.1

Keller, S., Vargas, C., Zhao, H., Piszczek, G., Brautigam, C. A., and Schuck, P. (2012). High-precision isothermal titration calorimetry with automated peakshape analysis. Anal. Chem. 84, 5066-5073. doi: 10.1021/ac3007522

Kessler, B., de Lorenzo, V., and Timmis, K. N. (1992). A general system to integrate lacZ fusions into the chromosomes of gram-negative eubacteria: regulation of the Pm promoter of the TOL plasmid studied with all controlling elements in monocopy. Mol. Gen. Genet. 233, 293-301. doi: 10.1007/BF00587591

Kim, H. E., Shitashiro, M., Kuroda, A., Takiguchi, N., and Kato, J. (2007). Ethylene chemotaxis in Pseudomonas aeruginosa and other Pseudomonas species. Microb. Environ. 22, 186-189. doi: 10.1263/jbb.106.1

Koch, B., Jensen, L. E., and Nybroe, O. (2001). A panel of Tn7-based vectors for insertion of the gfp marker gene or for delivery of cloned DNA into Gramnegative bacteria at a neutral chromosomal site. J. Microbiol. Methods 45, 187-195. doi: 10.1016/S0167-7012(01)00246-9

Kolodziej, A. F., Tan, T., and Koshland, D. E. Jr. (1996). Producing positive, negative, and no cooperativity by mutations at a single residue located at the subunit interface in the aspartate receptor of Salmonella typhimurium. Biochemistry 35, 14782-14792. doi: 10.1021/bi961481v

Kovach, M. E., Elzer, P. H., Hill, D. S., Robertson, G. T., Farris, M. A., Roop, R. M. II, et al. (1995). Four new derivatives of the broad-host-range cloning vector PBBR1MCS, carrying different antibiotic-resistance cassettes. Gene 166, 175-176. doi: 10.1016/0378-1119(95)00584-1

Krell, T. (2008). Microcalorimetry: a response to challenges in modern biotechnology. Microb. Biotechnol. 1, 126-136. doi: 10.1111/j.1751-7915.2007. 00013.x

Krell, T. (2015). Tackling the bottleneck in bacterial signal transduction research: high-throughput identification of signal molecules. Mol. Microbiol. 96, 685-688. doi: 10.1111/mmi.12975

Kuroda, A., Kumano, T., Taguchi, K., Nikata, T., Kato, J., and Ohtake, H. (1995). Molecular cloning and characterization of a chemotactic transducer gene in Pseudomonas aeruginosa. J. Bacteriol. 177, 7019-7025. doi: 10.1128/jb.177.24. 7019-7025.1995

Lacal, J., Alfonso, C., Liu, X., Parales, R. E., Morel, B., Conejero-Lara, F., et al. (2010a). Identification of a chemoreceptor for tricarboxylic acid cycle intermediates: differential chemotactic response towards receptor ligands. J. Biol. Chem. 285, 23126-23136. doi: 10.1074/jbc.M110.110403

Lacal, J., Garcia-Fontana, C., Callejo-Garcia, C., Ramos, J. L., and Krell, T. (2011a). Physiologically relevant divalent cations modulate citrate recognition by the McpS chemoreceptor. J. Mol. Recognit. 24, 378-385. doi: 10.1002/jmr. 1101

Lacal, J., Garcia-Fontana, C., Munoz-Martinez, F., Ramos, J. L., and Krell, T. (2010b). Sensing of environmental signals: classification of chemoreceptors according to the size of their ligand binding regions. Environ. Microbiol. 12, 2873-2884. doi: 10.1111/j.1462-2920.2010.02325.x

Lacal, J., Munoz-Martinez, F., Reyes-Darias, J. A., Duque, E., Matilla, M., Segura, A., et al. (2011b). Bacterial chemotaxis towards aromatic hydrocarbons in Pseudomonas. Environ. Microbiol. 13, 1733-1744. doi: 10.1111/j.1462-2920. 2011.02493.x
Laue, T. M., Shah, B. D., Ridgeway, T. M., and Pelletier, S. L. (1992). "Computeraided interpretation of analytical sedimentation data for proteins," in Analytical Ultracentrifugation in Biochemistry and Polymer Science, eds S. Harding, A. Rowe, and J. Horton (Cambridge: Royal Society of Chemistry), 90-125.

Li, W., and Lu, C. D. (2007). Regulation of carbon and nitrogen utilization by $\mathrm{CbrAB}$ and NtrBC two-component systems in Pseudomonas aeruginosa. J. Bacteriol. 189, 5413-5420. doi: 10.1128/JB.00432-07

Lin, L. N., Li, J., Brandts, J. F., and Weis, R. M. (1994). The serine receptor of bacterial chemotaxis exhibits half-site saturation for serine binding. Biochemistry 33, 6564-6570. doi: 10.1021/bi00187a025

Liu, Y. C., Machuca, M. A., Beckham, S. A., Gunzburg, M. J., and Roujeinikova, A. (2015). Structural basis for amino-acid recognition and transmembrane signalling by tandem Per-Arnt-Sim (tandem PAS) chemoreceptor sensory domains. Acta Crystallogr. D. Biol. Crystallogr. 71, 2127-2136. doi: 10.1107/ S139900471501384X

López-Farfán, D., Reyes-Darias, J. A., and Krell, T. (2016). The expression of many chemoreceptor genes depends on the cognate chemoeffector as well as on the growth medium and phase. Curr. Genet. doi: 10.1007/s00294-016-0646-7 [Epub ahead of print].

Luu, R. A., Kootstra, J. D., Nesteryuk, V., Brunton, C. N., Parales, J. V., Ditty, J. L., et al. (2015). Integration of chemotaxis, transport and catabolism in Pseudomonas putida and identification of the aromatic acid chemoreceptor PcaY. Mol. Microbiol. 96, 134-147. doi: 10.1111/mmi.12929

Martinez-Garcia, P. M., Lopez-Solanilla, E., Ramos, C., and RodriguezPalenzuela, P. (2016). Prediction of bacterial associations with plants using a supervised machine-learning approach. Environ. Microbiol. doi: 10.1111/14622920.13389 [Epub ahead of print].

Martin-Mora, D., Reyes-Darias, J. A., Ortega, A., Corral-Lugo, A., Matilla, M. A., and Krell, T. (2016). McpQ is a specific citrate chemoreceptor that responds preferentially to citrate/metal ion complexes. Environ. Microbiol. 18, 3284-3295. doi: 10.1111/1462-2920.13030

Matilla, M. A., Espinosa-Urgel, M., Rodriguez-Herva, J. J., Ramos, J. L., and Ramos-Gonzalez, M. I. (2007). Genomic analysis reveals the major driving forces of bacterial life in the rhizosphere. Genome Biol. 8, R179. doi: 10.1186/ gb-2007-8-9-r179

Matsunaga, T., Okamura, Y., Fukuda, Y., Wahyudi, A. T., Murase, Y., and Takeyama, H. (2005). Complete genome sequence of the facultative anaerobic magnetotactic bacterium Magnetospirillum sp. strain AMB-1. DNA Res. 12, 157-166. doi: 10.1093/dnares/dsi002

McKellar, J. L., Minnell, J. J., and Gerth, M. L. (2015). A high-throughput screen for ligand binding reveals the specificities of three amino acid chemoreceptors from Pseudomonas syringae pv. actinidiae. Mol. Microbiol. 96, 694-707. doi: 10.1111/mmi.12964

McLaughlin, H. P., Caly, D. L., Mccarthy, Y., Ryan, R. P., and Dow, J. M. (2012). An orphan chemotaxis sensor regulates virulence and antibiotic tolerance in the human pathogen Pseudomonas aeruginosa. PLoS ONE 7:e42205. doi: 10.1371/ journal.pone. 0042205

Milburn, M. V., Prive, G. G., Milligan, D. L., Scott, W. G., Yeh, J., Jancarik, J., et al. (1991). Three-dimensional structures of the ligand-binding domain of the bacterial aspartate receptor with and without a ligand. Science 254, 1342-1347. doi: $10.1126 /$ science. 1660187

Milligan, D. L., and Koshland, D. E. Jr. (1993). Purification and characterization of the periplasmic domain of the aspartate chemoreceptor. J. Biol. Chem. 268, 19991-19997.

Morgan, R., Kohn, S., Hwang, S. H., Hassett, D. J., and Sauer, K. (2006). BdlA, a chemotaxis regulator essential for biofilm dispersion in Pseudomonas aeruginosa. J. Bacteriol. 188, 7335-7343. doi: 10.1128/JB.00599-06

Ninfa, A. J., and Jiang, P. (2005). PII signal transduction proteins: sensors of alpha-ketoglutarate that regulate nitrogen metabolism. Curr. Opin. Microbiol. 8, 168-173. doi: 10.1016/j.mib.2005.02.011

O'Connor, J. R., Kuwada, N. J., Huangyutitham, V., Wiggins, P. A., and Harwood, C. S. (2012). Surface sensing and lateral subcellular localization of WspA, the receptor in a chemosensory-like system leading to c-di-GMP production. Mol. Microbiol. 86, 720-729. doi: 10.1111/mmi.12013

Oku, S., Komatsu, A., Nakashimada, Y., Tajima, T., and Kato, J. (2014). Identification of Pseudomonas fluorescens chemotaxis sensory proteins for malate, succinate, and fumarate, and their involvement in root colonization. Microbes Environ. 29, 413-419. doi: 10.1264/jsme2.ME14128 
Oku, S., Komatsu, A., Tajima, T., Nakashimada, Y., and Kato, J. (2012). Identification of chemotaxis sensory proteins for amino acids in Pseudomonas fluorescens Pf0-1 and their involvement in chemotaxis to tomato root exudate and root colonization. Microbes Environ. 27, 462-469. doi: 10.1264/jsme2. ME12005

Ortega, A., and Krell, T. (2014). The HBM domain: introducing bimodularity to bacterial sensing. Protein Sci. 23, 332-336. doi: 10.1002/pro.2410

Parales, R. E., Luu, R. A., Chen, G. Y., Liu, X., Wu, V., Lin, P., et al. (2013). Pseudomonas putida F1 has multiple chemoreceptors with overlapping specificity for organic acids. Microbiology 159, 1086-1096. doi: 10.1099/mic.0. 065698-0

Parkinson, J. S., Hazelbauer, G. L., and Falke, J. J. (2015). Signaling and sensory adaptation in Escherichia coli chemoreceptors: 2015 update. Trends Microbiol. 23, 257-266. doi: 10.1016/j.tim.2015.03.003

Petrova, O. E., and Sauer, K. (2012). Dispersion by Pseudomonas aeruginosa requires an unusual posttranslational modification of BdlA. Proc. Natl. Acad. Sci. U.S.A. 109, 16690-16695. doi: 10.1073/pnas.1207832109

Pineda-Molina, E., Reyes-Darias, J. A., Lacal, J., Ramos, J. L., Garcia-Ruiz, J. M., Gavira, J. A., et al. (2012). Evidence for chemoreceptors with bimodular ligandbinding regions harboring two signal-binding sites. Proc. Natl. Acad. Sci. U.S.A. 109, 18926-18931. doi: 10.1073/pnas.1201400109

Rahme, L. G., Ausubel, F. M., Cao, H., Drenkard, E., Goumnerov, B. C., Lau, G. W., et al. (2000). Plants and animals share functionally common bacterial virulence factors. Proc. Natl. Acad. Sci. U.S.A. 97, 8815-8821. doi: 10.1073/pnas.97.16. 8815

Reyes-Darias, J. A., Garcia, V., Rico-Jimenez, M., Corral-Lugo, A., Lesouhaitier, O., Juarez-Hernandez, D., et al. (2015a). Specific gamma-aminobutyrate chemotaxis in pseudomonads with different lifestyle. Mol. Microbiol. 97, 488-501. doi: 10.1111/mmi.13045

Reyes-Darias, J. A., Yang, Y., Sourjik, V., and Krell, T. (2015b). Correlation between signal input and output in PctA and PctB amino acid chemoreceptor of Pseudomonas aeruginosa. Mol. Microbiol. 96, 513-525. doi: 10.1111/mmi.12953

Rico-Jimenez, M., Munoz-Martinez, F., Garcia-Fontana, C., Fernandez, M., Morel, B., Ortega, A., et al. (2013). Paralogous chemoreceptors mediate chemotaxis towards protein amino acids and the non-protein amino acid gamma-aminobutyrate (GABA). Mol. Microbiol. 88, 1230-1243. doi: 10.1111/ mmi.12255

Rico-Jimenez, M., Reyes-Darias, J. A., Ortega, A., Diez Pena, A. I., Morel, B., and Krell, T. (2016). Two different mechanisms mediate chemotaxis to inorganic phosphate in Pseudomonas aeruginosa. Sci. Rep. 6, 28967. doi: 10.1038/ srep28967

Sampedro, I., Parales, R. E., Krell, T., and Hill, J. E. (2015). Pseudomonas chemotaxis. FEMS Microbiol. Rev. 39, 17-46. doi: 10.1111/1574-6976.12081

Scharf, B. E., Hynes, M. F., and Alexandre, G. M. (2016). Chemotaxis signaling systems in model beneficial plant-bacteria associations. Plant Mol. Biol. 90, 549-559. doi: 10.1007/s11103-016-0432-4

Schuck, P. (2000). Size-distribution analysis of macromolecules by sedimentation velocity ultracentrifugation and Lamm equation modeling. Biophys. J. 78, 1606-1619. doi: 10.1016/S0006-3495(00)76713-0

Schwarzer, C., Fischer, H., and Machen, T. E. (2016). Chemotaxis and binding of Pseudomonas aeruginosa to scratch-wounded human cystic fibrosis airway epithelial cells. PLoS ONE 11:e0150109. doi: 10.1371/journal.pone.0150109

Schweizer, H. P. (1992). Allelic exchange in Pseudomonas aeruginosa using novel ColE1-type vectors and a family of cassettes containing a portable oriT and the counter-selectable Bacillus subtilis sacB marker. Mol. Microbiol. 6, 1195-1204. doi: 10.1111/j.1365-2958.1992.tb01558.x

Stover, C. K., Pham, X. Q., Erwin, A. L., Mizoguchi, S. D., Warrener, P., Hickey, M. J., et al. (2000). Complete genome sequence of Pseudomonas aeruginosa PAO1, an opportunistic pathogen. Nature 406, 959-964. doi: 10.1038/35023079

Taguchi, K., Fukutomi, H., Kuroda, A., Kato, J., and Ohtake, H. (1997). Genetic identification of chemotactic transducers for amino acids in Pseudomonas aeruginosa. Microbiology 143(Pt 10), 3223-3229. doi: 10.1099/00221287-143$10-3223$
Tatke, G., Kumari, H., Silva-Herzog, E., Ramirez, L., and Mathee, K. (2015). Pseudomonas aeruginosa MifS-MifR two-component system is specific for alpha-ketoglutarate utilization. PLOS ONE 10:e0129629. doi: 10.1371/journal. pone.0129629

Tawaraya, K., Horie, R., Saito, S., Wagatsuma, T., Saito, K., and Oikawa, A. (2014). Metabolite profiling of root exudates of common bean under phosphorus deficiency. Metabolites 4, 599-611. doi: 10.3390/metabo4030599

Upadhyay, A. A., Fleetwood, A. D., Adebali, O., Finn, R. D., and Zhulin, I. B. (2016). Cache domains that are homologous to, but different from PAS domains comprise the largest superfamily of extracellular sensors in prokaryotes. PLoS Comput. Biol. 12:e1004862. doi: 10.1371/journal.pcbi.1004862

Vistica, J., Dam, J., Balbo, A., Yikilmaz, E., Mariuzza, R. A., Rouault, T. A., et al. (2004). Sedimentation equilibrium analysis of protein interactions with global implicit mass conservation constraints and systematic noise decomposition. Anal. Biochem. 326, 234-256. doi: 10.1016/j.ab.2003.12.014

Walker, T. S., Bais, H. P., Deziel, E., Schweizer, H. P., Rahme, L. G., Fall, R., et al. (2004). Pseudomonas aeruginosa-plant root interactions. Pathogenicity, biofilm formation, and root exudation. Plant Physiol. 134, 320-331. doi: 10.1104/ pp.103.027888

Watts, K. J., Taylor, B. L., and Johnson, M. S. (2011). PAS/poly-HAMP signalling in Aer-2, a soluble haem-based sensor. Mol. Microbiol. 79, 686-699. doi: 10.1111/ j.1365-2958.2010.07477.x

Webb, B. A., Helm, R. F., and Scharf, B. E. (2016). Contribution of individual chemoreceptors to Sinorhizobium meliloti chemotaxis towards amino acids of host and nonhost seed exudates. Mol. Plant Microbe Interact. 29, 231-239. doi: 10.1094/MPMI-12-15-0264-R

Woodcock, D. M., Crowther, P. J., Doherty, J., Jefferson, S., Decruz, E., Noyer-Weidner, M., et al. (1989). Quantitative evaluation of Escherichia coli host strains for tolerance to cytosine methylation in plasmid and phage recombinants. Nucleic Acids Res. 17, 3469-3478. doi: 10.1093/nar/17.9.3469

Wu, H., Kato, J., Kuroda, A., Ikeda, T., Takiguchi, N., and Ohtake, H. (2000). Identification and characterization of two chemotactic transducers for inorganic phosphate in Pseudomonas aeruginosa. J. Bacteriol. 182, 3400-3404. doi: 10.1128/JB.182.12.3400-3404.2000

Wuichet, K., and Zhulin, I. B. (2010). Origins and diversification of a complex signal transduction system in prokaryotes. Sci. Signal. 3, ra50. doi: 10.1126/ scisignal.2000724

Yamamoto, K., and Imae, Y. (1993). Cloning and characterization of the Salmonella typhimurium-specific chemoreceptor Tcp for taxis to citrate and from phenol. Proc. Natl. Acad. Sci. U.S.A. 90, 217-221. doi: 10.1073/pnas.90.1.217

Yu, D., Ma, X., Tu, Y., and Lai, L. (2015). Both piston-like and rotational motions are present in bacterial chemoreceptor signaling. Sci. Rep. 5, 8640. doi: 10.1038/ srep08640

Zusman, D. R., Scott, A. E., Yang, Z., and Kirby, J. R. (2007). Chemosensory pathways, motility and development in Myxococcus xanthus. Nat. Rev. Microbiol. 5, 862-872. doi: 10.1038/nrmicro1770

Conflict of Interest Statement: The authors declare that the research was conducted in the absence of any commercial or financial relationships that could be construed as a potential conflict of interest.

The reviewer BES and handling Editor declared their shared affiliation, and the handling Editor states that the process nevertheless met the standards of a fair and objective review.

Copyright (c) 2016 Martín-Mora, Ortega, Reyes-Darias, García, López-Farfán, Matilla and Krell. This is an open-access article distributed under the terms of the Creative Commons Attribution License (CC BY). The use, distribution or reproduction in other forums is permitted, provided the original author(s) or licensor are credited and that the original publication in this journal is cited, in accordance with accepted academic practice. No use, distribution or reproduction is permitted which does not comply with these terms. 